\title{
REVALIDATION STUDIES OF MARK 16 EXPERIMENTS: J70 (U)
}

\author{
by \\ Si Young Lee \\ Westinghouse Savannah River Company \\ Savannah River Site \\ Aiken, South Carolina 29808
}

DOE Contract No. DE-AC09-89SR18035

This paper was prepared in connection with work done under the above contract number with the U. S. Department of Energy. By acceptance of this paper, the publisher and/or recipient acknowledges the U. S. Government's right to retain a nonexclusive, royalty-free license in and to any copyright covering this paper, along with the right to reproduce and to authorize others to reproduce all or part of the copyrighted paper. 


\section{DISCLAIMER}

This report was prepared as an account of work sponsored by an agency of the United States Government. Neither the United States Government nor any agency thereof, nor any of their employees, makes any warranty, express or implied, or assumes any legal liability or responsibility for the accuracy, completeness, or usefulness of any information, apparatus, product, or process disclosed, or represents that its use would not infringe privately owned rights. Reference herein to any specific commercial product, process, or service by trade name, trademark, manufacturer, or otherwise does not necessarily constitute or imply its endorsement, recommendation, or favoring by the United States Government or any agency thereof. The views and opinions of authors expressed herein do not necessarily state or reflect those of the United. States Government or any agency thereof.

This report has been reproduced directly from the best available copy.

Available to DOE and DOE contractors from the Office of Scientific and Technical Information, P. O. Box 62, Oak Ridge, TN 37831; prices available from (615) $576-3401$.

Available to the public from the National Technical Information Service, U. S. Department of Commerce, 5285 Port Royal Rd., Springfield, VA 22161 


\section{DELETED \\ VERSION .}

SAVANNAH RIVER TECHNOLOGY CENTER

Applied Technology Section

Applied Physics Group

SRT-CMA-930058

\section{Revalidation Studies of Mark 16 Experiments: J70 (U)}

October 25, 1993

By:

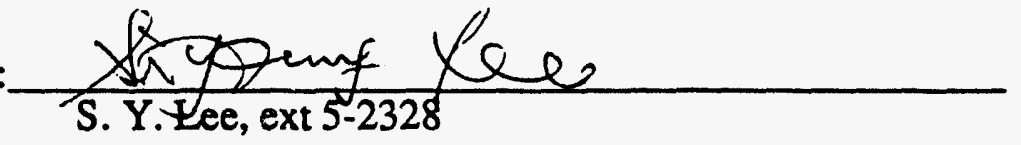

Review By: $\frac{\substack{\text { R. L. Reed, ext 5-3468 } \\ \text { Fellow Engineer }}}{10-25-93}$

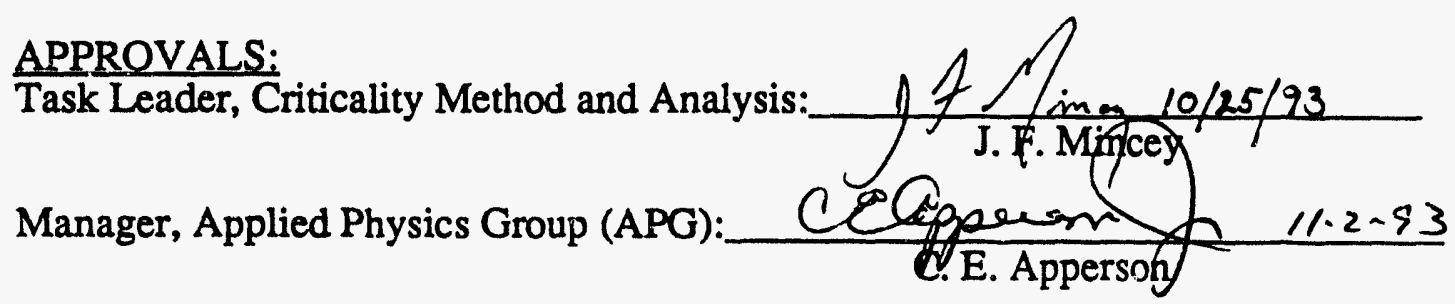

The original copy of this document contains unclassified controlled nuclear information (UCNI) which is to be protected pursuant to Section 148 of the Atomic Energy Act of 1954, as amended (42 U.S.C. 2168), and Department of Energy Regulation 10 C.F.R. 1017. To provide this document for public review, UCNI information has been deleted pursuant to these regulations.

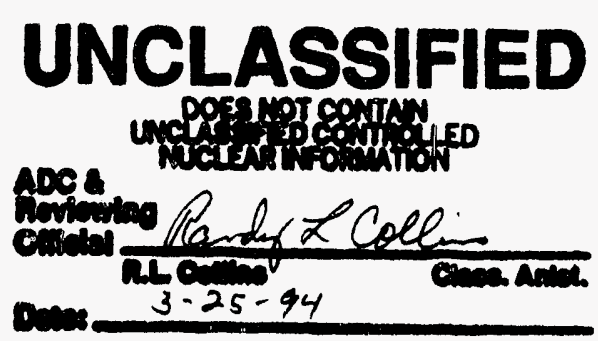

Distribution List:
S. Y. Lee, $773-11 \mathrm{~A}$
C. E. Apperson, 773-42A
R. L. Reed, $773-42 \mathrm{~A}$
R. L. Webb 786-1A
E. F. Trumble
$786-1 A$
M. A. Rosser, 705-K

M. R. Buckner, $773-42 \mathrm{~A}$

T. G. Williamson, $773-42 \mathrm{~A}$

J. F. Mincey, R. W. Rathbun, T. A. Reilly, $773-22 \mathrm{~A}$ $786-1 \mathrm{~A}$ $707-\mathrm{F}$

Technical Information Management, 703-43A 
SRT-CMA-930058

Page 2 of 29

October 25, 1993

\section{INTRODUCTION AND SUMMARY}

The MGBS-TGAL combination of the 770 criticality modules $^{1}$ was validated for Mark 16 lattices by H. K. Clark as reported in DPST-83-1025 2. Unfortunately, the records of the calculations reported can not be retrieved and the descriptions of the modeling used are not fully provided in DPST-83-1025. The report does not describe in detail how to model the experiments and how to set up the input. The computer output for the cases reported in the memorandum can not be located in files.

The MGBS-TGAL calculations reported in DPST-83-1025 have been independently reperformed to provide retrievable record copies of the calculations, to provide a detailed description and discussion of the methodology used, and to serve as a training exercise for a novice criticality safety engineer. The current results reproduce Clark's reported results to within about $0.01 \%$ or better. A procedure to perform these and similar calculations is given in this report, with explanation of the methodology choices provided. The procedure is described by providing two detailed examples. Results are summarized in Table 2. Finally, copies of the computer output have been made via microfiche and will be maintained in APG files.

\section{DISCUSSION}

\section{KOKO-MGBS-TGAL}

MGBS and TGAL are modular computer codes, described in DPSTM-86-700-31, used at SRS to perform criticality calculations. MGBS provides 12-group and 2-group multigroup diffusion parameters and macroscopic cross sections, primarily for arrays of materials in water. TGAL employs macroscopic cross sections, diffusion parameters such as provided by MGBS, and lattice description parameters to perform onedimensional transverse buckling searches, which are combined by KOKO to generate the reactivity parameter, $\mathrm{K}_{\mathrm{eff}}$, for the lattice. In addition to the original cross section formulation in MGBS, an alternate formulation has been provided in MGBS and is commonly used for criticality analyses.

TGAL solves the one-dimensional two-group steady-state diffusion equation analytically for slab, cylindrical, and spherical geometries. The diffusion equation solution is effective for regions containing fissionable material, moderator, and structural material. For thin, strong absorbing regions, TGAL can apply the collision probability method since diffusion thecry' is not accurate in strong absorbing regions. The cadmium sheets in a couple of the experiments analyzed here are such regions.

The MGEX record is expected when the EXPT option is specified for the MGBS module. From data provided in the MGEX record, KOKO writes the input records for MGBS and TGAL for a heterogeneous cell with equal pitch sizes in a regular array. It should be pointed out that a lattice with different pitch sizes can not be modeled just by records created by KOKO directly from the MGEX record. The TGAL records generated by the MGEX input record must be modified to match the lattice geometry desired.

\section{DESCRIPTIONS OF THE MARK 16 EXPERIMENTS}

The Mark 16 experiments ${ }^{3}$ modeled by Clark were subcritical lattices in water. The lattices were generally $2 \times 3,2 \times 4,3 \times 3$, and $4 \times 4$ arrays of Mark 16 fuel, frequently with assemblies in contact within rows and rows separated by as much as several inches 
SRT-CMA-930058

Page 3 of 29

October 25, 1993

of water. For several experiments, aluminum-clad cadmium sheets were inserted between rows. No targets were inserted in the fuel assemblies. The Mark 16 dimensions as modeled are shown in Figure 12. Ribs in the assemblies are indirectly modeled, consistent with Clark's practice. Clark included the volume of the ribs in the outer cladding of the inner and middle fuel tubes, maintaining total aluminum volume.

Table 2 indicates each experimental lattice modeled. Three different fuel compositions were modeled, corresponding to Oralloy, and ${ }^{236} \mathrm{U} /{ }^{235} \mathrm{U}$ ratios of 0.19 and 0.74 , as shown in Table 1. The aluminum content of each fuel region was calculated by KOKO using standard formulas and densities of uranium and aluminum as discussed in DPSTM-86700-3. The experiments involved measuring $\mathrm{K}^{2}$, the square of the inverse relaxation length, for various subcritical arrays of these lattices when moderated and fully reflected with $\mathrm{H}_{2} \mathrm{O}$. The measured $\mathrm{k}^{2}$ values were used by the experimenters to determine $\mathrm{K}_{\mathrm{eff}}{ }^{3}$.

\section{PROCEDURE}

Clark reported MGBS-TGAL calculations for the arrays indicated in Table 2. However, the file copies of the computer output are not retrievable and the descriptions of the calculations provided in DPST-83-1025 did not detail the methods and input data used. An explicit modeling of several lattices in MGBS and TGAL input records did not produce the same results as reported by Clark. He indicated the driver module KOKO was used to generate the MGBS and TGAL input data via the MGEX record.

The MGBS-TGAL combination via the MGEX record under KOKO can directly provide calculations only for uniform fuel lattice arrays with equal pitch in both dimensions ( $x$ and $y$ coordinates). To perform calculations for arrays with different pitches between rows of assemblies than between assemblies in a row, a multistep procedure must be used to accurately model the arrays.

A general procedure using the MGBS-TGAL module combination under KOKO to determine the effective multiplication factor $\left(\mathrm{K}_{\text {eff }}\right)$ corresponding to a subcritical experiment has been established. In the following text, upper case courier type designates the invariant portion of the record names, and lower case courier type designates the user-specified portion of the record names. Note that detailed directions to create the KOKO input records are provided in DPSTM-86-700-3. The procedure is as follows:

1. Create the following input records corresponding to the uniform array for the experiment:

INPUT.KOKO. ? jobname

INPUT . KOKO. MGEX. ?name

where ?jobname is the job dataset name and ?name is the study designation name.

In the INPUT. KOKO. ? jobname record, specify execution of MGBS-TGAL with the EXPT option.

2. Execute KOKO (J70 JOSHUA system).

3. Copy the following input records generated by $\mathrm{KOKO}$ to the user data set:

INPUT . MGBS . CONTROL . ? name . ?n

INPUT.MGBS . TYPE. ?name. ?n

INPUT.MGBS.RADII . ?name 
INPUT . TGAL . ? jobname

INPUT. TGAL. BTCH. ? name. ?btch number

INPUT. TGAI. CMBN. ?name

4. Modify INPUT. TGAL. BTCH. ?name. ?btch number records to match the lattice geometry desired. Note that this record requires dimensions in centimeters. (The INPUT . TGAL. BTCH. ? name. ?btch number record is required for each dimension explicitly modeled.)

5. Modify the INPUT . KOKO. ? jobname record to specify execution of MGBS-TGAL without the EXPT option.

\section{Execute KOKO.}

7. Record the lattice $\mathrm{K}_{\text {eff }}$ from the KOKO output.

\section{EXAMPLES}

To demonstrate the general procedure, preparation of input records and problem execution two cases are provided here as examples.

- $2 \times 4$ array in water (a row of 4 assemblies in contact separated from an identical row by $2.3 "$ ) with $236 \mathrm{U}$ to $235 \mathrm{U}$ atom ratio $=0.19$.

- $4 \times 4$ array in water (4 rows of 4 assemblies at 3.838" pitch within row, rows separated by 1.3 " of water with an aluminum clad cadmium sheet between rows) with ${ }^{236} \mathrm{U}$ to ${ }^{235} \mathrm{U}$ atom ratio $=0.19$.

The arrays are shown in Figures 13 and 16.

\section{0.19 Ratio $2 \times 4$ Mark 16 Amay $\left(6.00^{\prime \prime} \times 3.70^{\prime \prime}\right)$}

The physical configuration of the Mark 16 array is illustrated in Figure 13. Figure 14 shows the uniform lattice model used to generate basic diffusion and macroscopic parameters via the MGEX record. TGAL uses these basic parameters to solve the twogroup diffusion equations for the lattice model of the physical array in Figure 13. The different pitch sizes and different number of material regions along the $x$ - and $y$ directions are shown in the one-dimensional slab models in Figure 15. The input records are provided in Figures 1 to 5 . Letters and numbers denoted in outlined italics in the input records are the input data.

Following the general procedure described above, the INPUT. KOKO. ? jobname record specifying execution of MGBS and TGAL with the EXPT option and the INPUT .KOKO.MGEX. ? name record are set up as shown in Figures 1 and 2 . The job name (SYLN4777) and study designation name (MK16M) provide linkage between the input records and with the job execution and are arbitary choices of the user. The MGEX input record shown in Figure 2 is expected if the EXPT option is specified for MGBS in the INPUT . KOKO. ? jobname record. Parameter choices for the MGEX record are detailed in Reference 1. The first page of the INPUT. KOKO.MGEX. ?name record specifies the dimensional and material content information for each region in a fuel assembly and the second page specifies the cell and lattice dimensions and axial buckling. The assembly dimensions are as indicated in Figure 12. The axial buckling data are from the $x^{2}$ values 
provided by Clark (Ref. 2) and given in Table 2. As can be seen in the last column of the second page in Figure 2, the negative value of the measured value $\left(k^{2}\right)$ is used as the axial buckling. The basis for this usage is provided in the Appendix. The third page of the record specifies the isotopic compositions of the materials. Note that water, as the moderator, need not be included in the material composition listing since KOKO assumes water is the material \#1 for the MGEX record.

Figure 1. Computer input record for Case I (INPUT . KOKO. ? jobname)

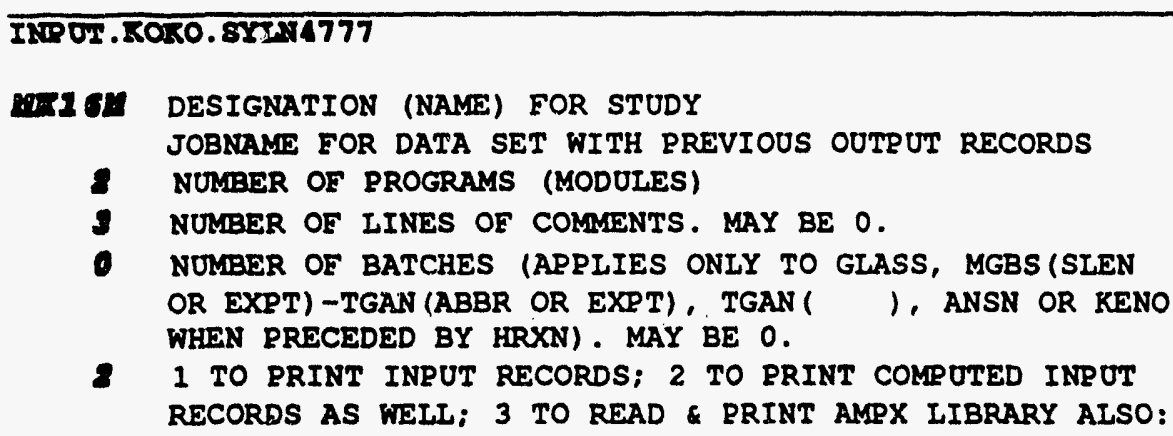

ORTIONAL INPOT RECORDS ARE-- INPOT.KOKO

. ADBN. ?NANE. ?N, .ANSN. ?NAME. ?N, .MGEX. ?NAME. ?N, . SLEN . ?NAME. ?N, .DISL. ?NAME. ,

. PADJ. ? NAME ? ?N, PROGRAM OPTION nete nesp

rens.

. GLSS . ?NAME. ?N, .THTR. ?NAME. ?N, OR .TSLA. ?NAME.

PAGE 1

IKR OT . KOTO. 8YTX4777

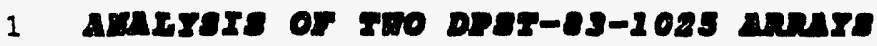

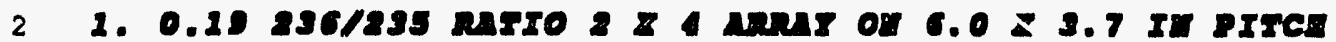

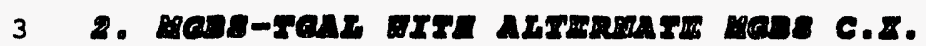


Figure 2. Computer input record for Case I (INPUT . KOKO. MGEX. ?name)

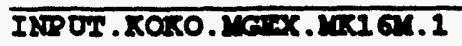

12 NO. OF REGIONS INSIDE EUEL O.D. FOR EACH REGION TYPE INDEX - RADIUS(CM) OR DIA(IN) ARE REQOIRED. THE DIMENSIONAI LIMIT FOR MGBS IS 22 REGIONS. MODERATOR IS TYPE 1 . SLIGHTLY ENRICHED URANIUM OR THORIUM MUST BE TYPE 2 FOR RESONANCE INTEGRAL FOR HETEROGENEOUS LATTICE DUE TO, HELLSTRAND OR WEITMAN TO BE REQUESTED.

\begin{tabular}{|c|c|c|c|c|c|}
\hline REGION & INDEX & DIMENSION & REGION & INDEX & DIMENSIC \\
\hline 1 & 1 & 1. 7100 & 2 & & 1.7500 \\
\hline $\begin{array}{l}3 \\
5\end{array}$ & 3 & 2.0240 & $\begin{array}{l}4 \\
6\end{array}$ & 8 & $\begin{array}{l}2.1010 \\
2.0500\end{array}$ \\
\hline 7 & 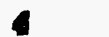 & 8.0760 & 8 & 2 & 320 \\
\hline 9 & 1 & .4910 & 10 & 2 & 3.4040 \\
\hline 11 & $s$ & 3.9400 & 12 & 2 & 3.7000 \\
\hline
\end{tabular}

PAGE $\quad 1$

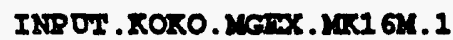

1 NUMBER of LATtices (NO. CELLS + RADII FROM P $1<51$ )

COLOMN 1 IS CELL RADIOS (CM) OR CELI DIA (IN) OR PITCH (IN)

COLUMN 2 IS LATTICE DIA OR WIDTH OR -NO. RODS. (O FOR.DIM SRCH)

COLUMN 3 IS HT, INGTH, AXIAL BCKLNG, OR BIAS(KEFF)--FOR DIM SRCH COLOMN 4 IS HT, AXIAL BCKLNG, OR CONC (FOR A DIMENSION SEARCH) :

$3.70000500 \quad 7.40000 \% 00 \quad 1.40000501 \quad-.229505-08$

PAGE 2

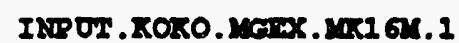

2 PITCH INDEX $(0,2$ OR 3)

33 REMAINING ITEMS

REMAINING ITEMS ARE DENSITY \& COMPOSITION FOR METAI OR OXIDE TYPES. ORDER IS DENSITY, NEGATIVE ELEMENT INDEX, ISOTOPIC COMPOSITION (WT U233, 0234, 0235, 0236, U238 EOR U; PU239, PU240, PU241, PU242 FOR PU), WEIGHT FRACTION OF ELEMENT, ETC., DENSITY, ETC. FOR DIMENSION SEARCH THESE MUST BE FOLLOWED BY DELTA KEFF: ELEMENT $O, U, P U, T H, A L, 2 R, F E, C R, N I, B, C D, G D, P B, C, B E$ INDEX $5,6,7,8,9,10,11,12,13,14,15,16,17,18,19$
2.70000500
$-.00000802$
2.000005 00
7. 420005-01
4.24000001
1.450005-01
1. 400005-02
$-.00000501$
0.00000900
I. 500005-02
$0.00000 \pi 00$
7. $20000 \pi-01$
-.00000\% o1
0.00000800
1.020005 02
$-.50000201$
0.00000 00
$0.00000=00$
0.00000800
1. 400003-02
7. $620005-01$
1.540008-01
1.04000503
I.900005-01
2. $900005-08$
$-.60000 \pi 01$
1.030005-01
-. c0000a 01
0.00000500
$-.90000 x$ ox
$0.100004-02$ 
Upon execution, KOKO generates MGBS and TGAL input records based on the KOKOMGEX input record for a uniform array. KOKO generates one TGAL.BTCH record with two cases and specifies each case with two regions (fuel cell and water regions) for this lattice. The procedure requires that two TGAL.BTCH records be used, to model different material regions and dimensions for each of the $\mathbf{x}$ - and $\mathbf{y}$-directions of the lattice model in Figure 15. Note that KOKO automatically sets up the lattices specified by the MGEX record as a lattice with $1000 \mathrm{~cm}$ of $\mathrm{H}_{2} \mathrm{O}$ on each side and also represents the lattice as reflected about the center in each direction. The following input records generated by KOKO (described in detail in DPSTM-86-700-3) must be copied to the user data set:

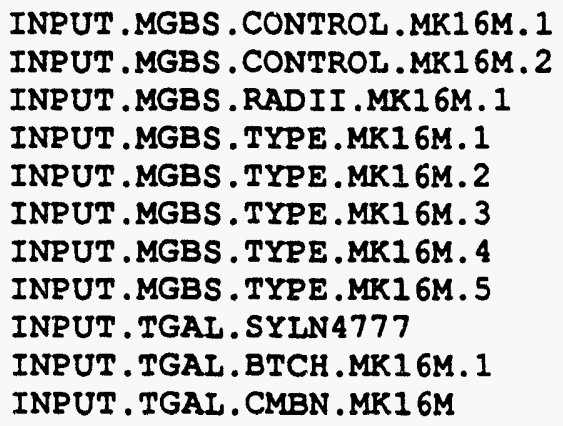

Then, the INPUT.TGAL. BTCH.MK16M. 1 record, which models both $\mathbf{x}$ and $\mathbf{y}$ dimensions uniformly, is modified to match the $x$-direction (within row) regions of the equivalent lattice in Figure 15. The number-of-cases parameter, shown in boldfaced italics in Figure 3 , is changed from 2 to 1 , and results in the y-direction region descriptions being eliminated from this record. The $\mathrm{x}$-direction (within row) regions are correctly modeled. The modified parameter is shown in boldfaced italics in Figure 3.

A similar, but different record, INPUT . TGAL. BTCH.MK16M.2, is then created to include the water region (between rows) of the equivalent lattice for the $y$-direction illustrated in Figure 15. The created input record is shown in Figure 4. In addition, the INPUT . KOKO. ? jobname record is modified to specify the KOKO execution of the MGBSTGAL combination without the EXPT option. The revised KOKO input record is shown in Figure 5. Then, KOKO is executed. The resulting effective multiplication factor, $\mathrm{K}_{\mathrm{eff}}$ is shown in Table 2.

\section{0.19 Ratio, $4 \times 4$ Mark 16 Array with Aluminum-Clad Cadmium Sheets between Rows (5.00" x 3.838")}

Figure 16 shows the physical configuration of the $4 \times 4$ Mark 16 fuel assembly array wirh cadmium poison plates.

Following the general procedure, INPUT.KOKO.? jobname and INPUT . KOKO.MGEX. ?name records are set up for a uniform lattice model of the $4 \times 4$ physical array, which is shown shown in Figure 17. The input records are shown in Figures 6 and 7. As shown in Figui. 7, aluminum metal and cadmium material compositions are also provided to generate additional MGBS records for the two materials in the aluminum clad cadmium plate between the rows of fuel assemblies as shown in Figure 16. These materials will be referenced in step 4 of the general procedure. 
SRT-CMA-930058

Page 8 of 29

October 25, 1993

Figure 3. Computer input record for Case I (INPUT. TGAL . BTCH . ? name . ?btch number)

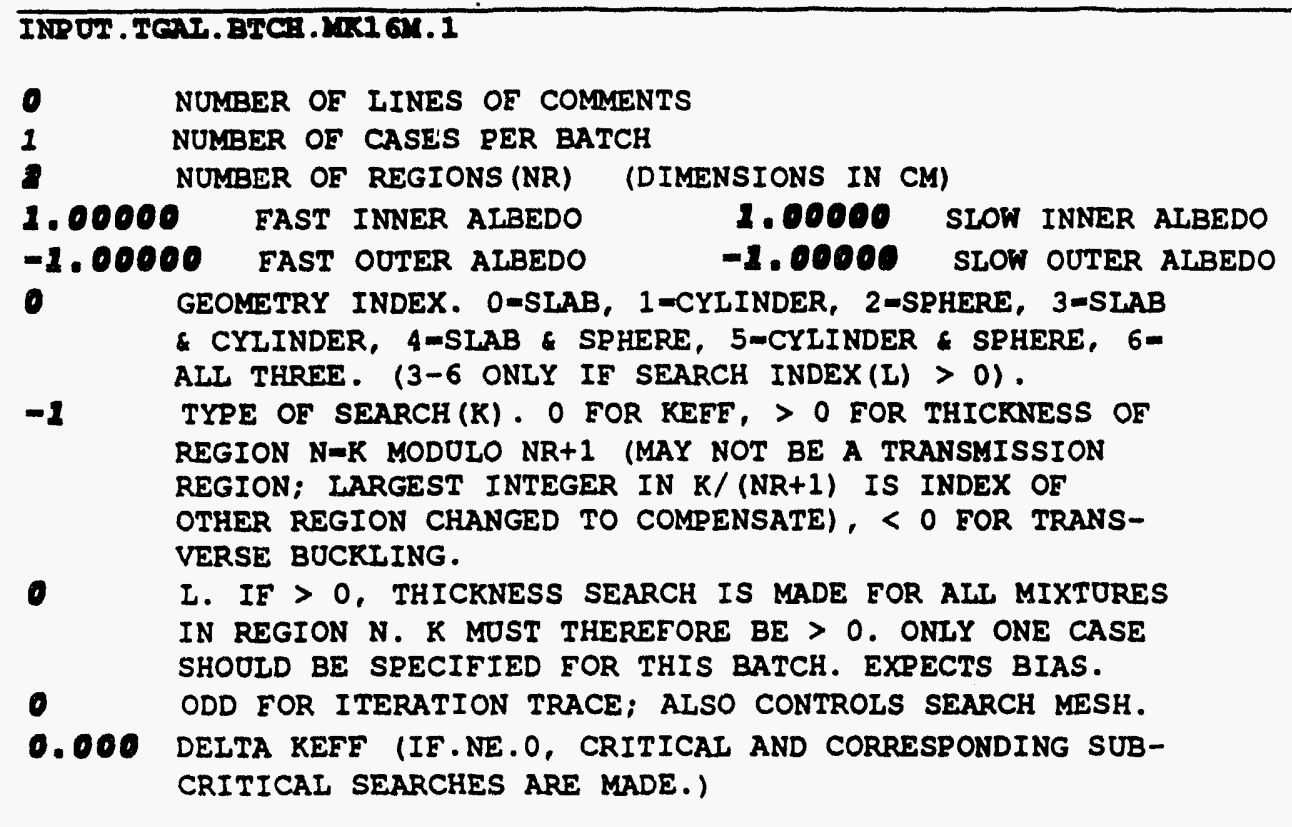

PAGE 1

INPOT . TEN . BTCH . 201 6X. 1

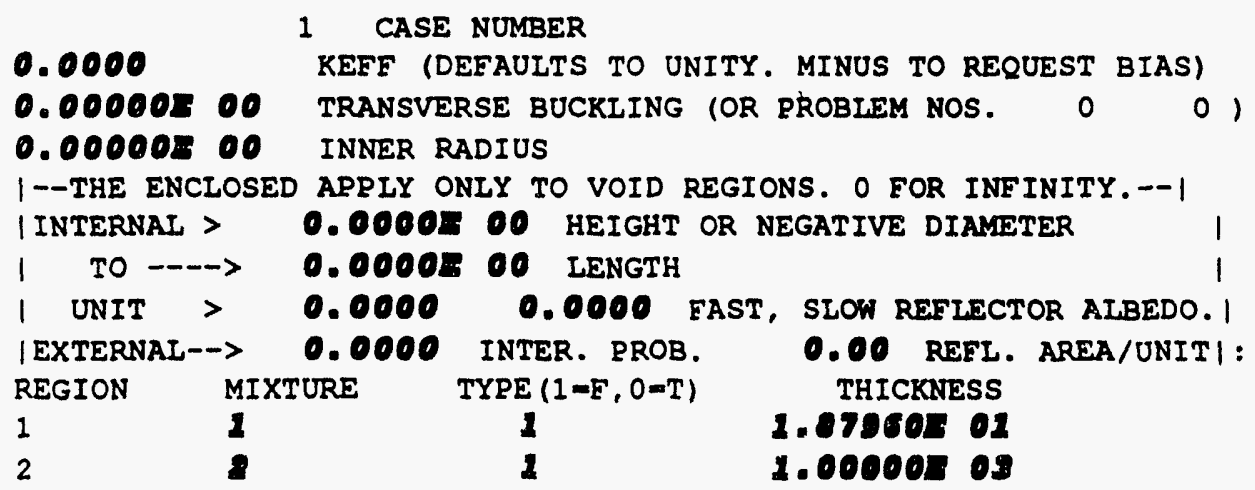


Figure 4. Revised computer input record for Case I (INPUT . TGAL. BTCH . ?name . ?btch number)

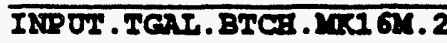

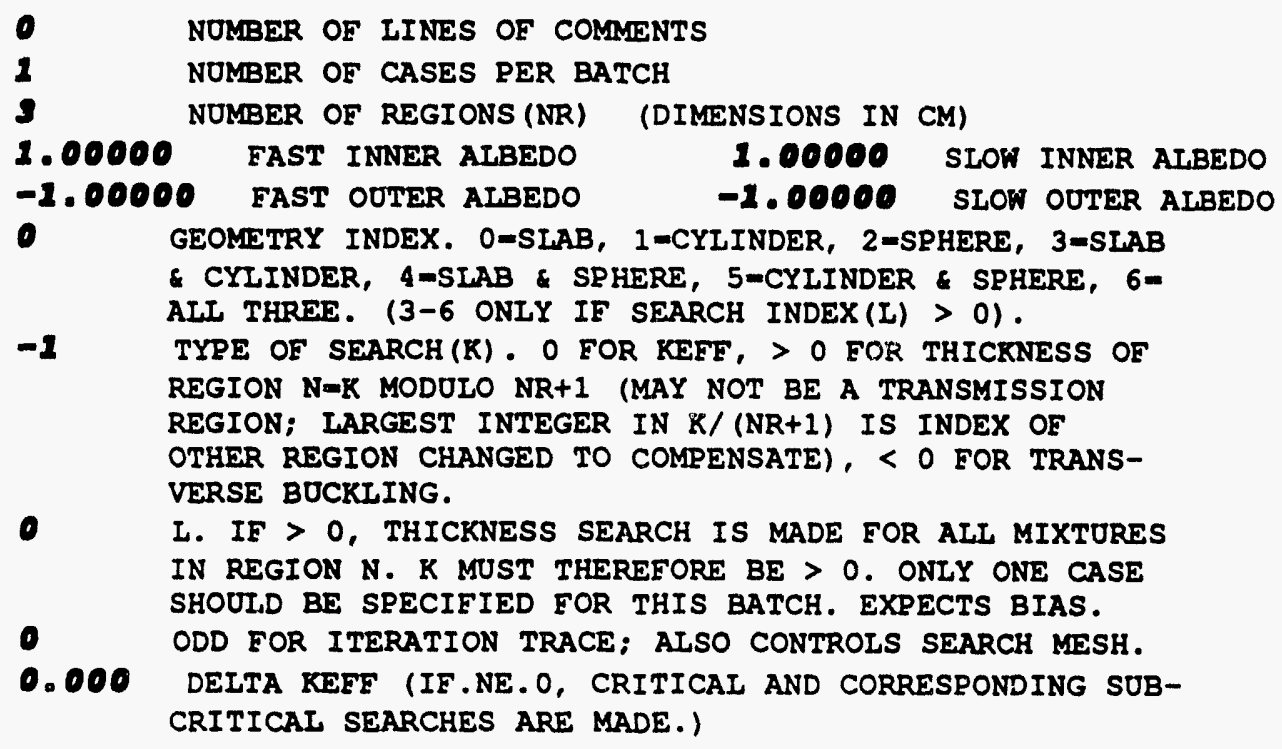

PAGE

1

IXPOT. TCAT. BTCR.MR16X.2

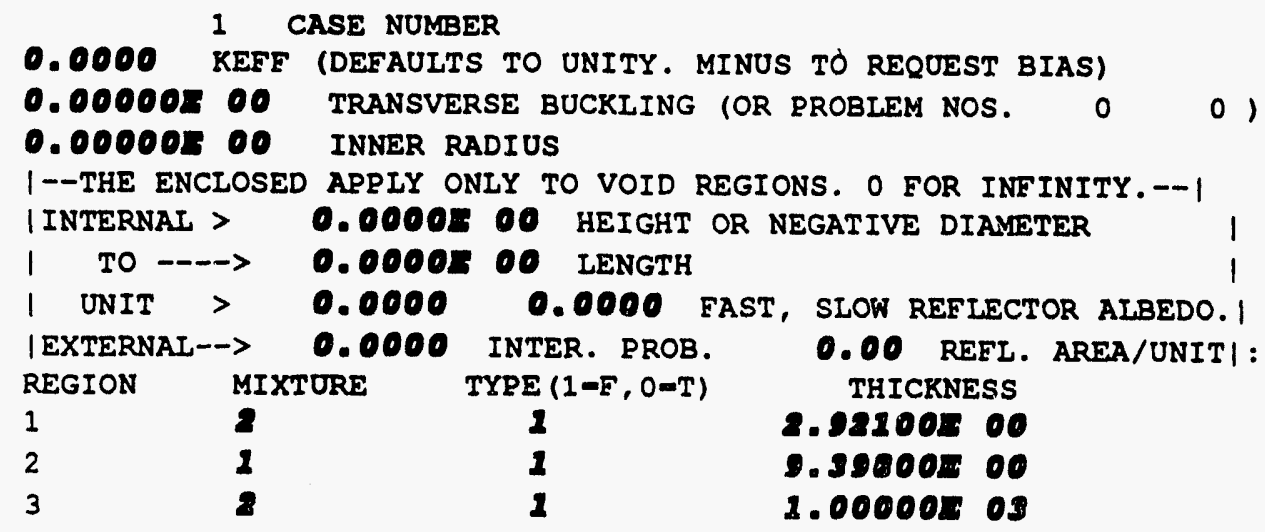


Figure 5. Revised computer input record for Case I (INPUT . koko. ? jobname)

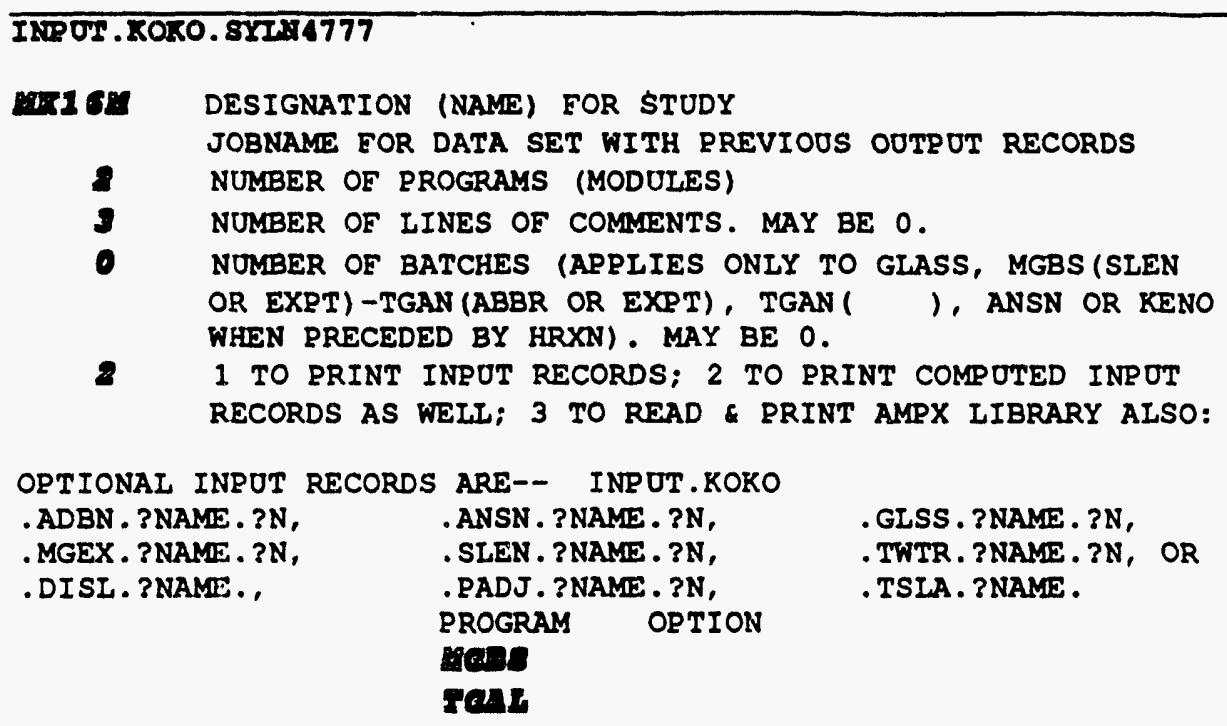

PAGE 1

IXPOT. XOKO. SYLM4777

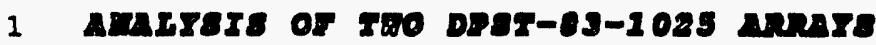

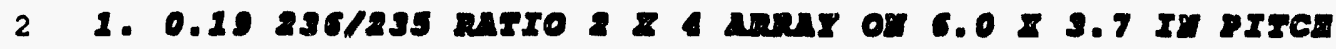

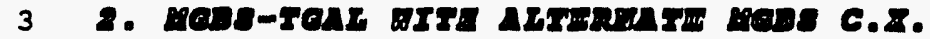


Figure 6. Computer input record for Case II (INPUT . Koko. 3 jobname) IXPOT.XOKO.8IC34777

Q2. 1-C2 DESIGNATION (NANE) FOR STUDY JOBNAME EOR DATA SET WITH PREVIOUS OUTPUT RECORDS

3 NUMBER OE PROGRAMS (MODULES)

3 NUMBer of LINES of comments. May be 0.

- number of batches (applies only to glass, mgbs (SLEN OR EXPT) -TGAN (ABBR OR EXPT), TGAN( ), ANSN OR KENO WHEN PRECEDED BY HRXN). MAY BE 0 .

21 TO PRINT INPOT RECORDS; 2 TO PRINT COMPUTED INPOT RECORDS AS WELL; 3 TO READ \& PRINT AMPX LIBRARY ALSO:

OPTIONAI INPUT RECORDS ARE-- INPUT.ROKO

. ADBN. ?NAME. ?N, MGEX. ? NAME. ?N, .DISL. ?NAME.

. ANSN. ?NAME. ?N, . SLEN. ?NAME. ?N, . PADJ. ?NAME. ?N, PROGRAM ORTION

ran Bres

rans rex 
Figure 7. Computer input record for Case II (INPUT .KOKO.MGEX. ?name)

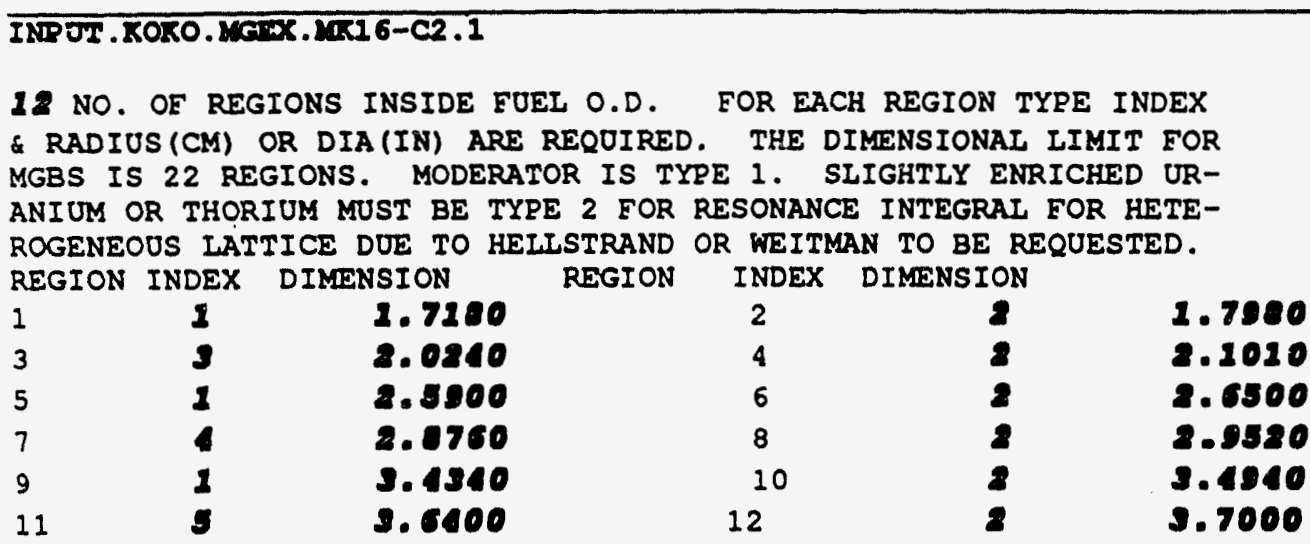

PAGE

1

IRPOT . KOKO. MaWX . MaK16-C2.1

1 NUMBER OF IATTICES (NO. CELLS + RADII EROM P $1<51$ )

COIUMN 1 IS CELL RADIUS (CM) OR CELI DIA (IN) OR PITCH (IN)

COLUMN 2 IS LATTICE DIA OR WIDTH OR -NO. RODS. (O FOR DIM SRCH)

COLUMN 3 IS HT, LNGTH, AXIAL BCKLNG, OR BIAS(KEEE)--FOR DIM SRCH COLUMN 4 IS HT, AXIAL BCKLNG, OR CONC (FOR A DIMENSION SEARCH) :
$3.93000 \pi 00$
1.3352002
1.53520: O1
$-.85000 \%-03$

PAGE

2

INP OT . KOTO MGWX .M16-C2.1

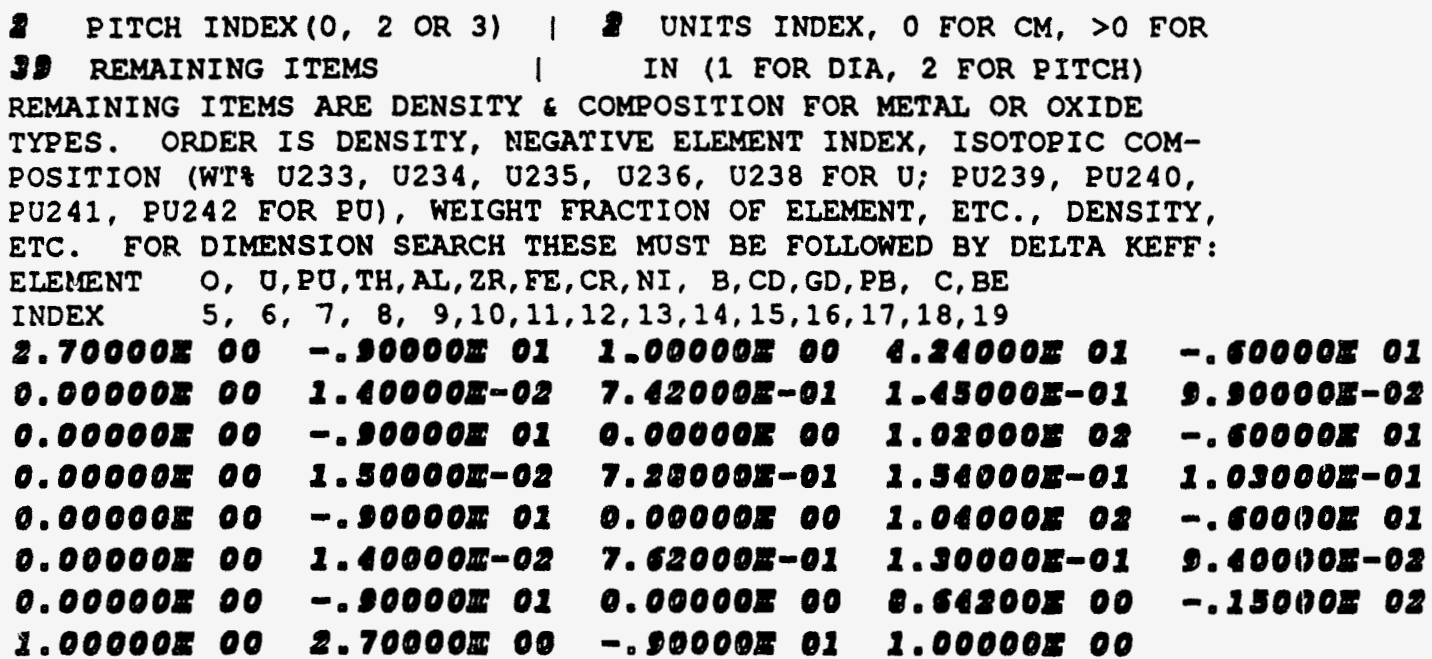


The following records generated by the execution of KOKO were copied to the user data set:

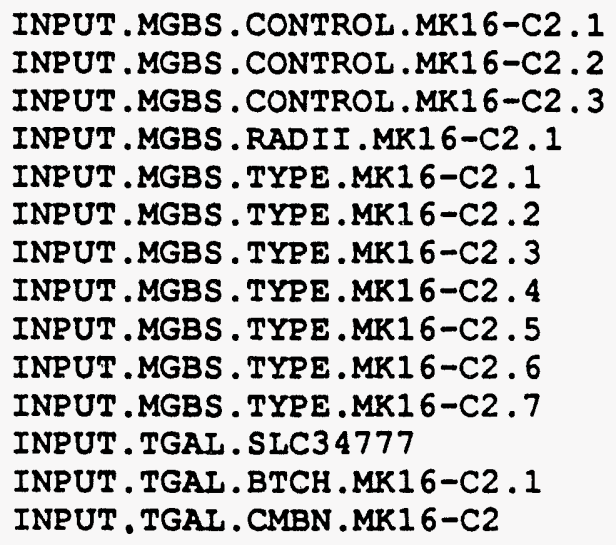

The TGAL.BTCH record created by KOKO provides TGAL input for both dimensions in the $x$ and $y$ directions, but the allowed indexing specifies the same number of regions in each dimension. To correctly and efficiently input the required TGAL data, a INPUT . TGAL . BTCH. ?name. ?btch number record is used for each dimension. The total number of TGAL batch cases remains as 2. If desired, multiple MGBS-TGAL cases can be run with a single set of records by specifying all materials in the MGEX record and creating TGAL batch cases for each dimension of each array. The TGAL.CMBN record then specifies how those cases are to be combined.

Among the records generated by the KOKO run, the INPUT.TGAL. BTCH.MK16-C2.1 record is modified to include only the $\mathrm{x}$-direction regions corresponding to the onedimensional slab model shown in Figure 18. The modified record is shown in Figure 8 with the changed parameters denoted in boldfaced italics. The INPUT . TGAL. BTCH.MK16$\mathrm{C2} .2$ record is created to include water moderator and cadmium poison regions between the rows of fuel assemblies in the y-direction as illustrated in Figure 18. This record contains 11 different material regions in the y-direction for the one-directional slab model, which is consistent with Figure 18. The created input record is shown in Figure 9. The strong absorber (Cd) region, where the diffusion approximation is not valid, is characterized by transmission and collision probabilities by specifying type $=0$ in the third column of the second page of Figure 9. Note that the aluminum cladding of the cadmium plate is modeled normally since it is a region of low absorption. The INPUT . KOKO. ? Jobname record is modified to specify the KOKO execution of MGBSTGAL combination without the EXPT option as shown in Figure 10. Then, KOKO is executed to get the $\mathrm{K}_{\text {eff }}$ result as shown in Table 2.

The examples provided used the standard alternate MGBS cross sections. To specify the original MGBS cross sections rather than the altemate MGBS cross sections, one modification is required in the TGAL record (before step 5 in the general procedure). The parameter for ORIGINAL MGBS XSECS AND TGAN SOLUTION, the fourth entry parameter of the INPUT. TGAL. ? jobname record, should be changed to 0 from 1 , which is the default number created by the KOKO-MGEX run. The modified parameter is shown in boldfaced italics in Figure 11. The results in Table 2 include $K_{\text {eff }}$ values for the formulations of both cross sections. 
Figure 8. Computer input record for Case II (INPUT . TGAL . BTCH. ?name . ?btch number)

PAGE

INPOT. TCN . BTCB. MC16-C2.1

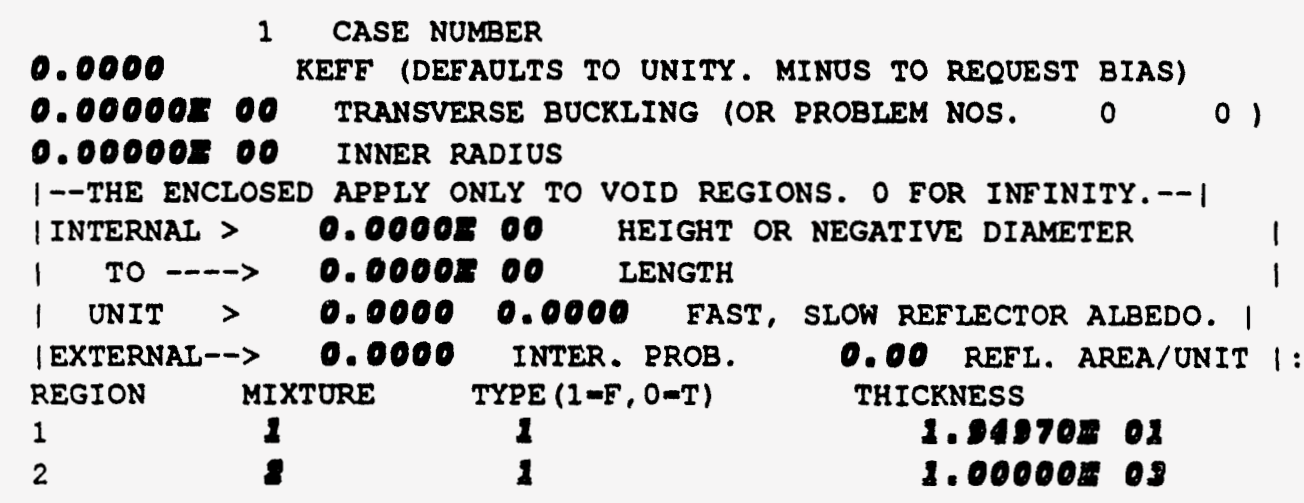


Figure 9. Revised computer input record for Case II (INPUT . TGAL . BTCH . ?name . ?btch number)

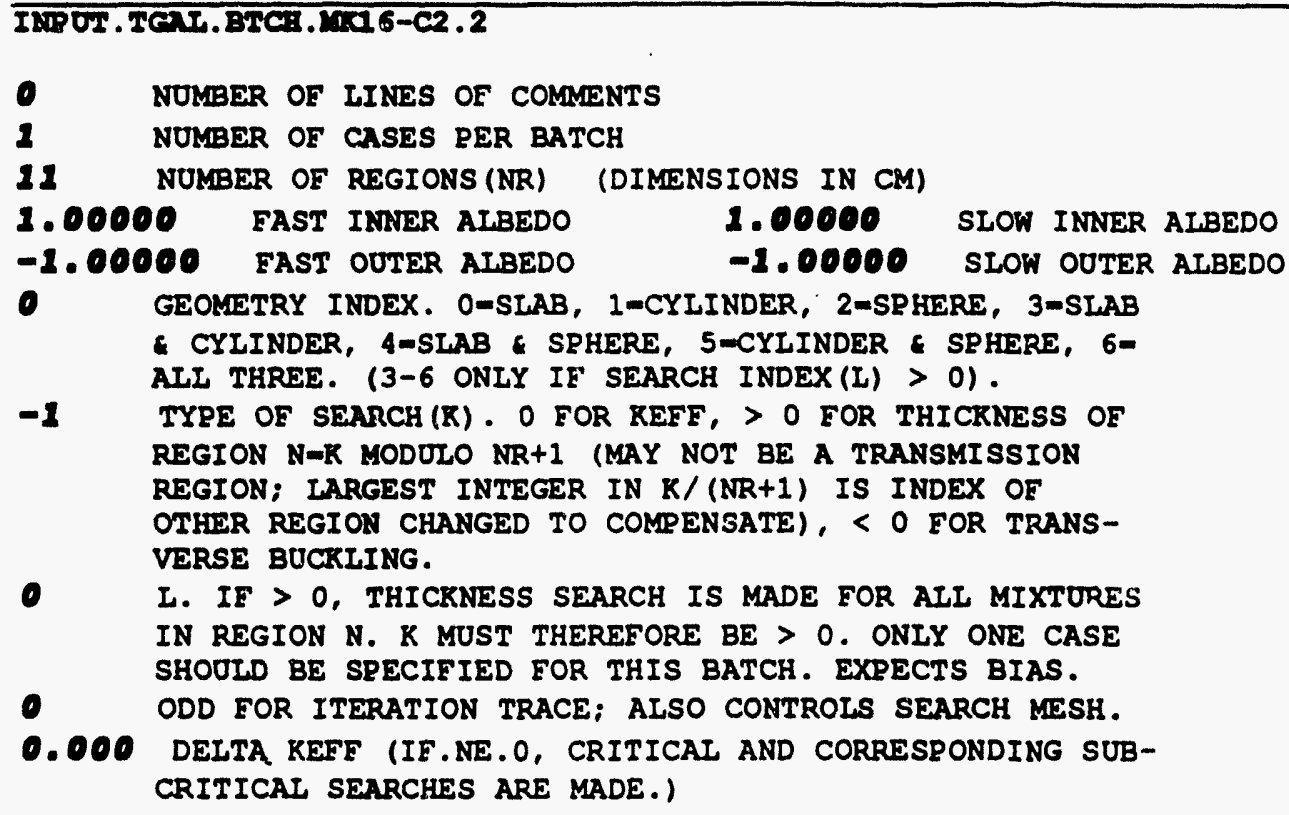

PAGE

1

IXP OT. TCAT. BTCR. M1, 6-C2 . 2

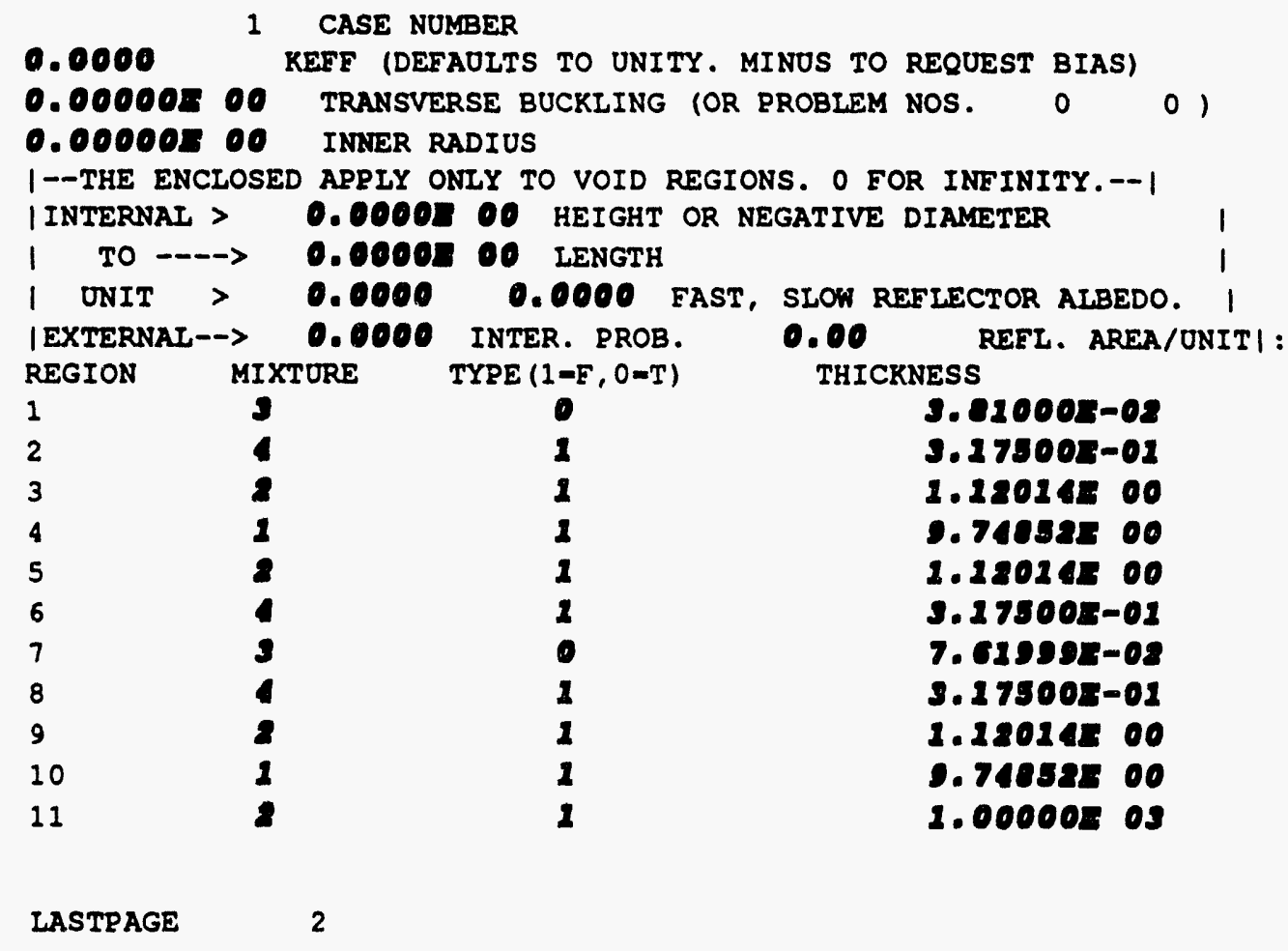


Figure 10. Revised computer input record for Case II (INPUT . KOKO . ? Jobname)

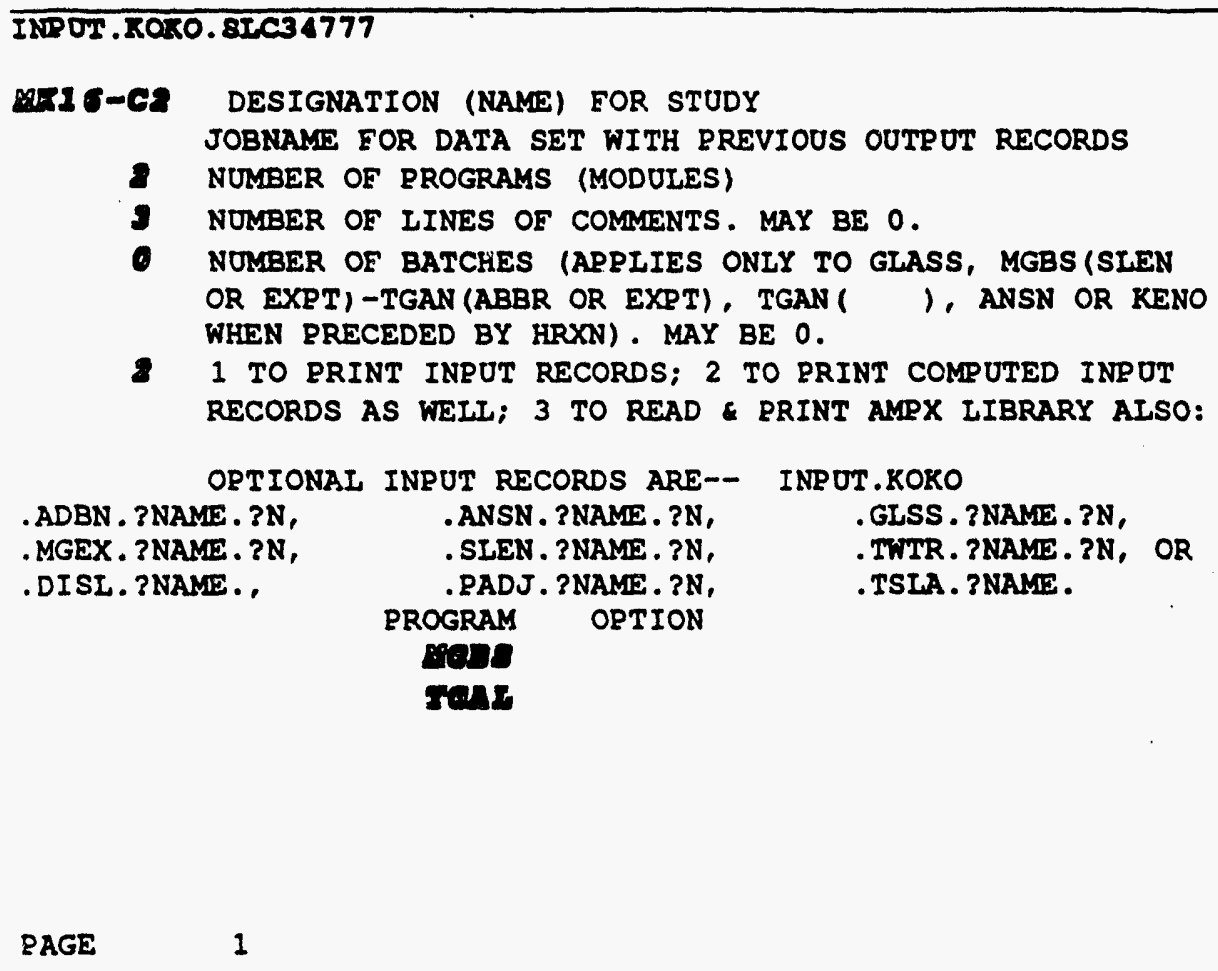

PAGE

1

INPOY . KOKO. SLC34777

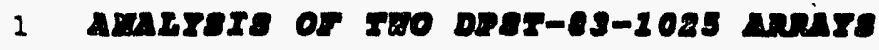

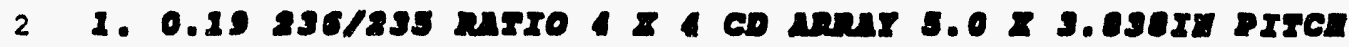

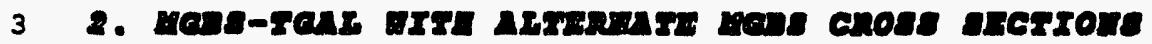


SRT-CMA-930058

Page 17 of 29

October 25, 1993

Figure 11. Computer input record specifying original MGBS cross sections

(INPUT.TGAL. ? jobname)

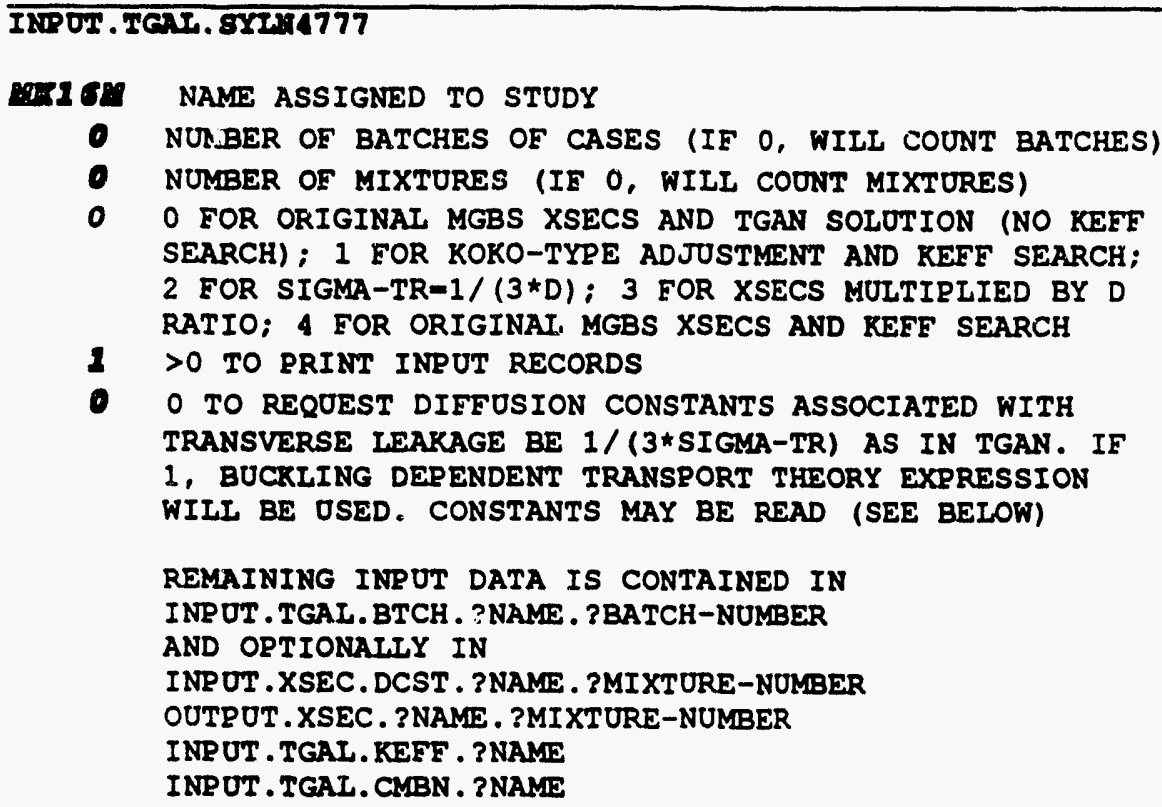

\section{RESULTS}

The procedure outlined in the previous section has been used to calculate $\mathrm{K}_{\mathrm{eff}}$ for each of the cases provided by Clark ${ }^{2}$. The results are provided in Table 2 . Calculations with both alternate and original MGBS cross sections are included as was done by Clark. Note that the present results deviate from Clark's results by only \pm 0.0001 (about $0.01 \%$ ) for 4 cases among the 30 cases delineated in Table 2. That deviation may be due to different computer systems (e.g., different compilers or different intrinsic math libraries) from that used by Clark. That deviation is insignificant in demonstrating that the described technique is equivalent to Clark's technique.

Convergence to the wrong root in transverse buckling searches may occur, especially in a multi-region problem such as a fuel assembly array with cadmium sheets inserted between rows. This happened in the $4 \times 4\left(5.0^{\prime \prime} \times 3.70^{\prime \prime}\right)$ array with an aluminum clad cadmium sheet between rows using the original MGBS cross section option (microfiche job number 5258 in Table 3). In this situation, a non-zero positive value of a transverse buckling in the INPUT. TGAL. BTCH. ?name. ?btch number record may be entered (default value $=0.0$ ). It serves as the initial guess to get correct convergence in a transverse buckling search. Different initial guesses do not affect the final result.

For information, the effect of including or not including the aluminum in the ribs as part of the fuel cladding was examined and found to be negligibly small. Modeling the ribs as added aluminum in the cladding yields $\mathrm{K}_{\text {eff }}$ about $0.5 \%$ less than modeling without considering the ribs. That is intuitively expected since including the ribs in the cladding reduces the total volume of moderator within the assembly and reduced moderator is generally expected to reduce the reactivity for arrays such as considered here. 
SRT-CMA-930058

Page 18 of 29

October 25, 1993

Lastly, the job record number for each calculation is shown in Table 3 to keep track of the microfiche outputs. The microfiche will be maintained in APG files for future retrieval and reference.

\section{CONCLUSION}

Clark's results have been independently reproduced. A technique has been demonstrated to prepare the KOKO input records and execute KOKO as intended by Clark for criticality calculations.

\section{REFERENCES}

1. H. K. Clark, "User's Manual, Joshua Nuclear Criticality Safety Modules", DPSTM-86700-3, March, 1987.

2. H. K. Clark, "Correlations with Mark 16 Experiments", DPST-83-1025, November 29, 1983.

3. R. L. Currie, "Nuclear Safety Measurements Using Special Mark 16 Fuel Tubes", DPST-70-462, September 15, 1970.

4. J. J. Duderstadt and L. J. Hamilton, Nuclear Reactor Analysis, John Wiley \& Sons, Inc., New York, 1976.

5. S. Glasstone and M. C. Edlund, The Elements of Nuclear Reactor Theory, D. Van Nostrand Company, Inc., New York, 1952. 


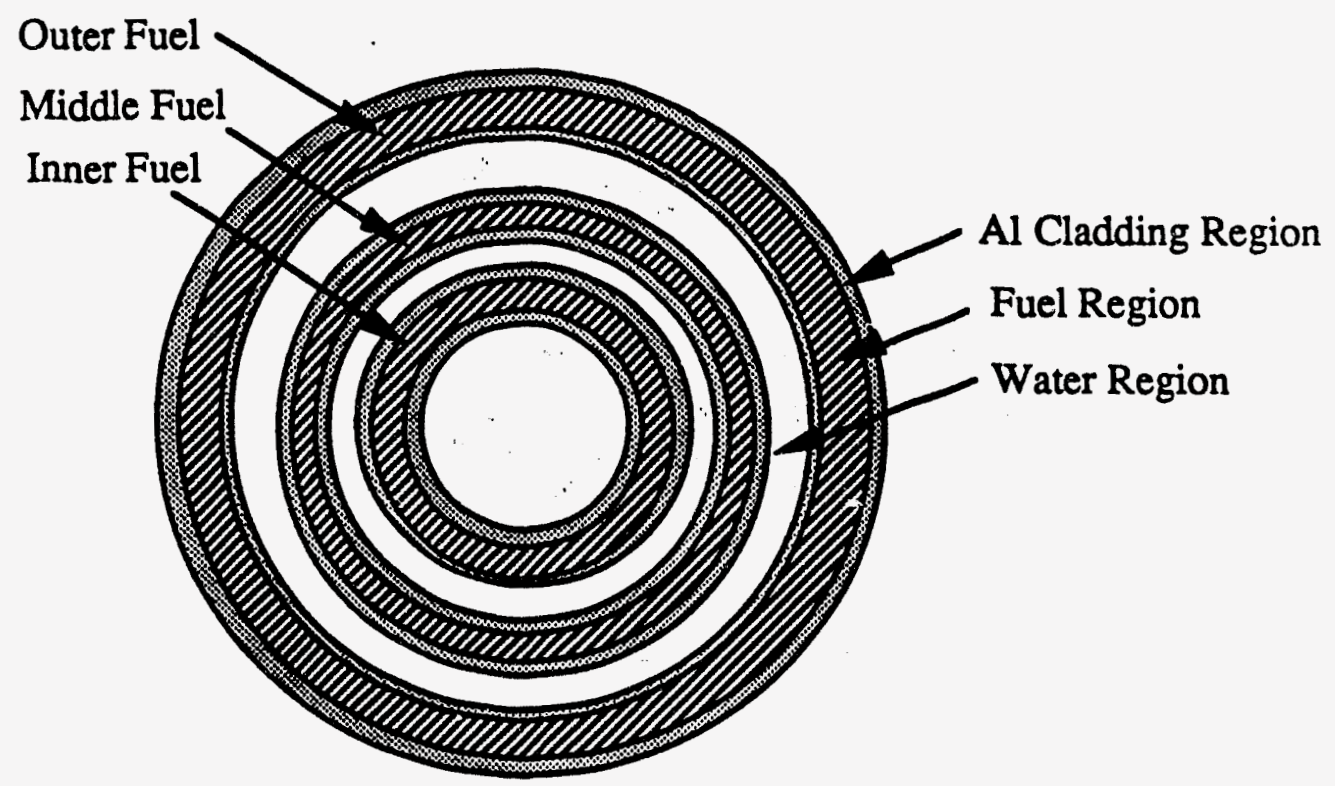

Inner Fuel Inner Cladding I. D. $\quad 1.718$ inch Inner Fuel Inner Cladding O. D. 1.798 inch Inner Fuel I. D. 1.798 inch Inner Fuel O. D. 2.024 inch Inner Fuel Outer Cladding I. D. $\quad 2.024$ inch Inner Fuel Ouer Cladding O. D. 2.101 inch Middle Fuel Inner Cladding I. D. 2.590 inch Middle Fuel Outer Cladding O. D. 2.650 inch Middle Fuel I. D. 2.650 inch Middle Fuel O. D. 2.876 inch Middle Fuel Outer Cladding I. D. 2.876 inch Middle Fuel Outer Cladding O. D. 2.952 inch Outer Fuel Inner Cladding I. D. 3.434 inch Outer Fuel Inner Cladding O. D. $\quad 3.494$ inch Outer Fuel I. D. 3.494 inch Outer Fuel O. D. 3.640 inch Outer Fuel Outer Cladding I. D. 3.640 inch Outer Fuel Outer Cladding O. D. 3.700 inch

Figure 12. Detailed dimensions of Mark 16 fuel assembly ${ }^{2}$ used in the input record, INPUT . KOKO.MGEX. ?name (note that ribs are accounted for using equivalent diameter.). 
SRT-CMA-930058

Page 20 of 29

October 25, 1993

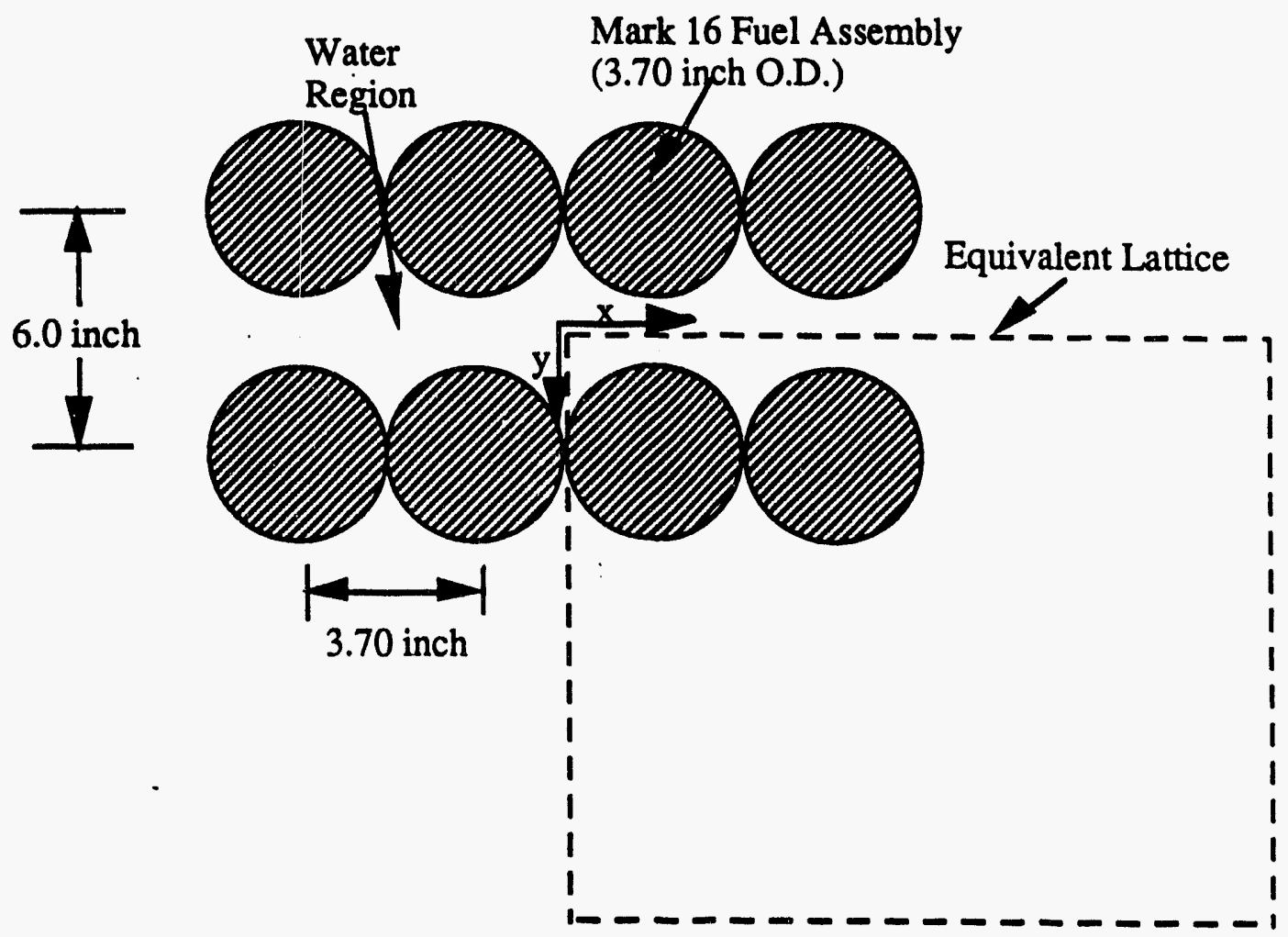

Figure 13. 2 x 4 Mark 16 array (6.00" x 3.70").

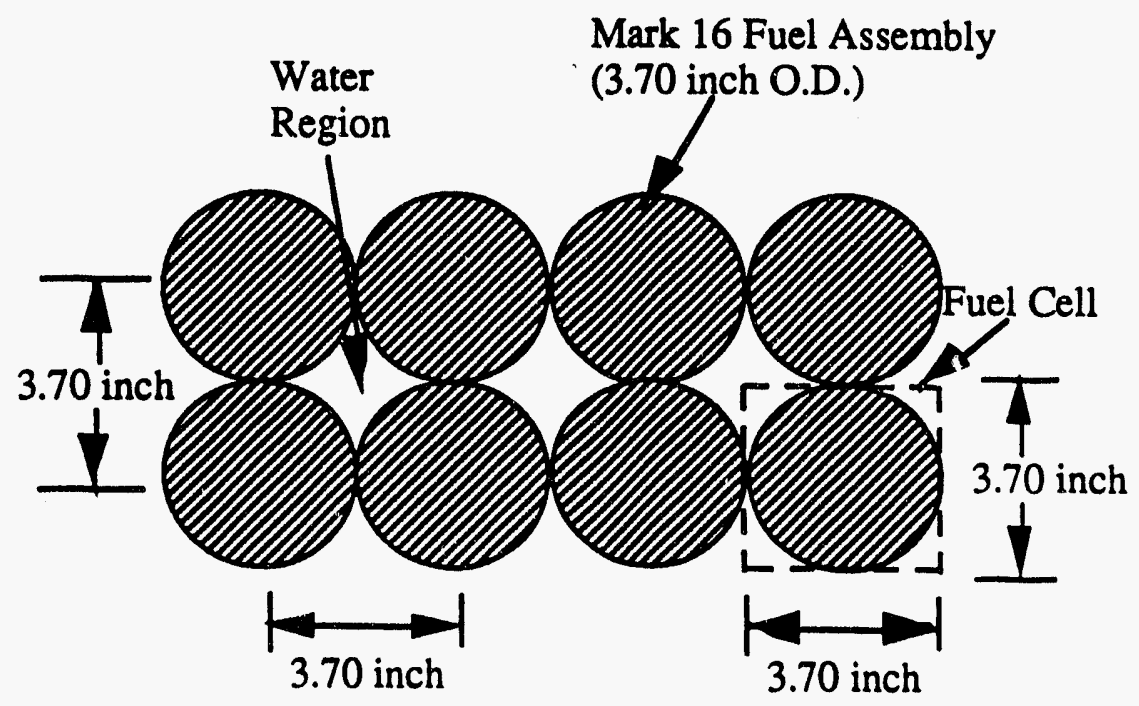

Figure 14. Uniform lattice model of 2 x 4 Mark 16 fuel assembly array as modeled in INPUT . KOKO. MGEX. MK16M.1 record. 

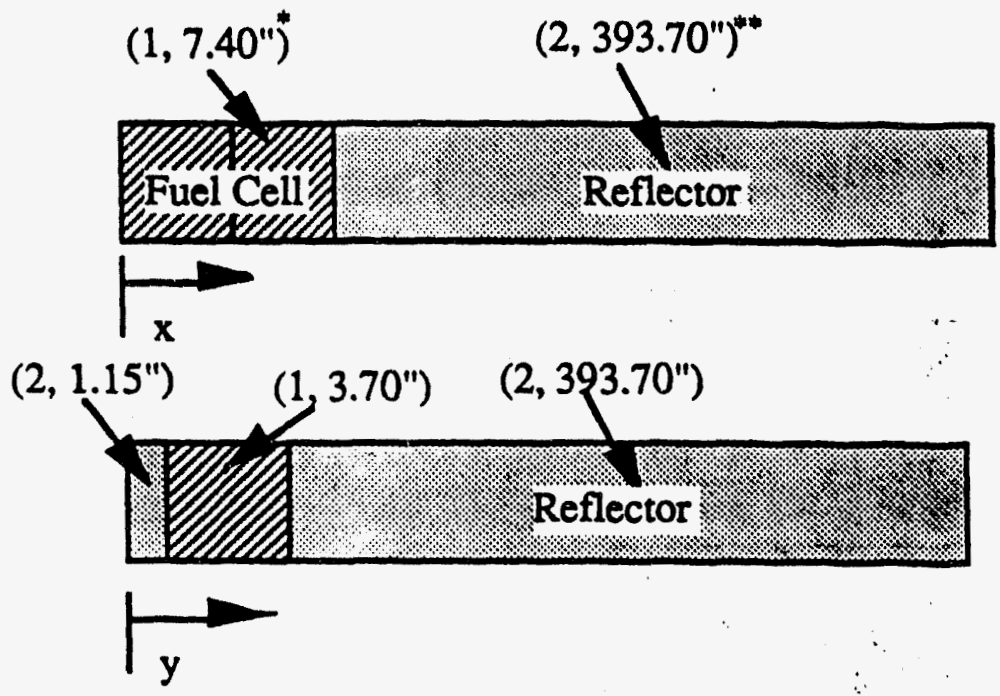

\begin{tabular}{|c|l|}
\hline Region Number & Materials \\
\hline 1 & Fuel Cell \\
2 & Water \\
\hline
\end{tabular}

- The first number in parenthesis indicates region number and the second thickness of each region in inch.

** 393.70 inch $(=1000 \mathrm{~cm}$ ) corresponds to large value of reflector thickness. (1000 $\mathrm{cm}$ is standard value provided by KOKO.)

Figure 15. Slab model for equivalent lattice of $2 \times 4$ Mark 16 array (dotted rectangle in Figure 13) for transverse buckling search as modeled in INPUT. TGAL.BTCH.MK16M.1 and INPUT . TGAL.BTCH.MK16M.2. 
SRT-CMA-930058

Page 22 of 29

October 25, 1993

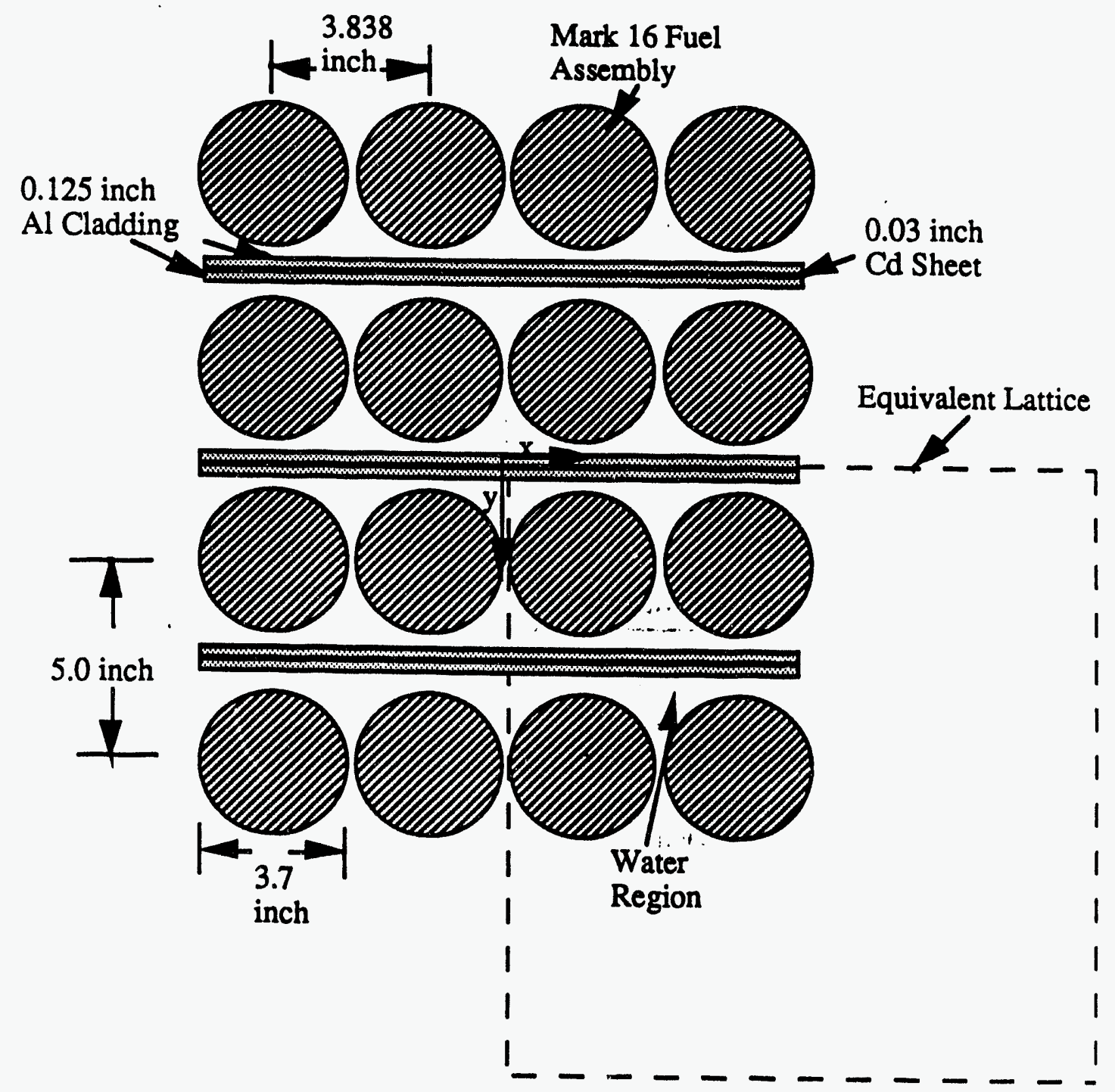

Figure 16. 4 x 4 Mark 16 fuel assembly array with $\mathrm{Al}$ clad $\mathrm{Cd}$ sheets between rows. 


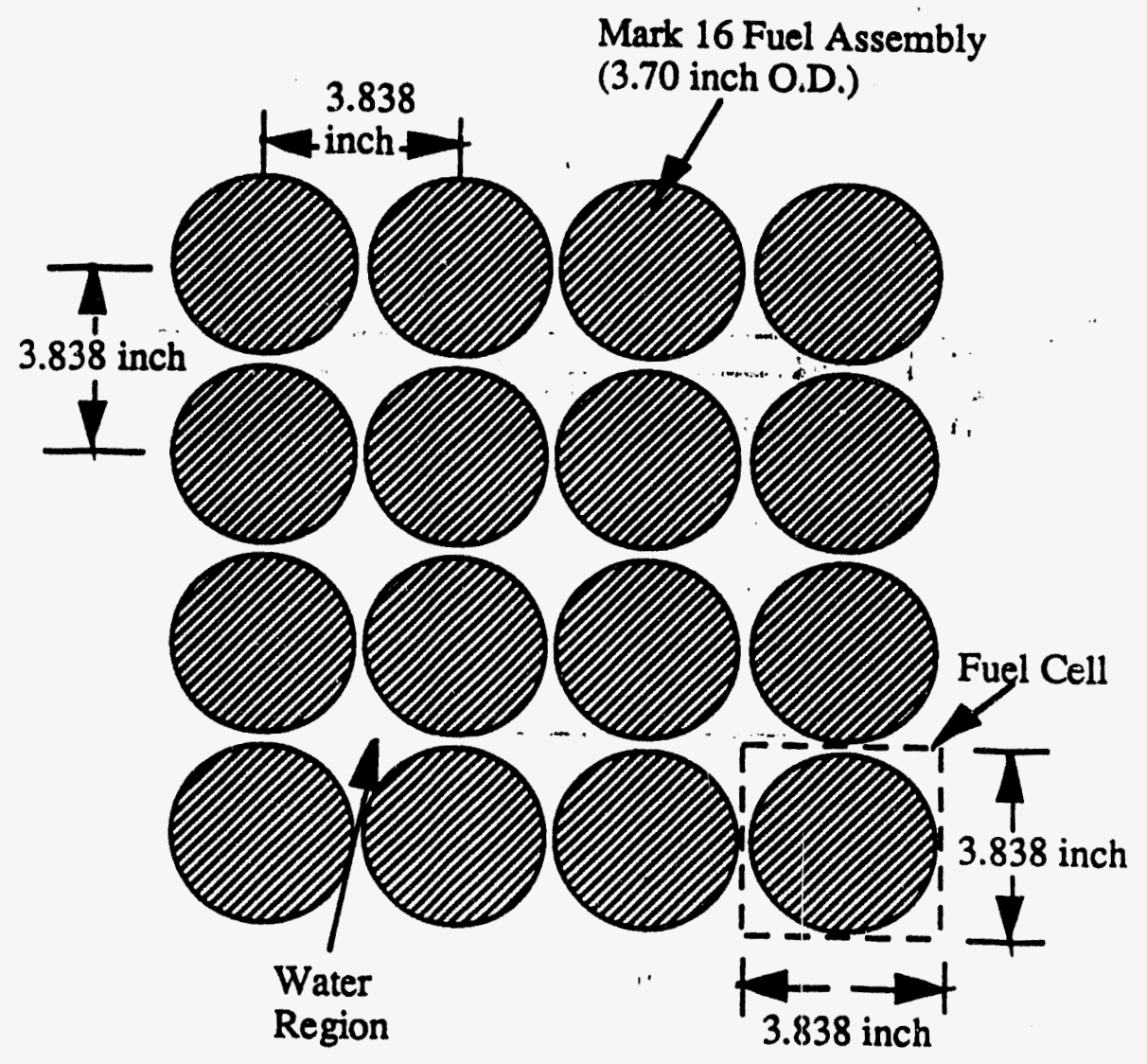

Figure 17. Uniform lattice model of $4 \times 4$ Mark 16 fuel assembly array as modeled in INPUT . KOKO.MGEX.MK16-C2. 1 record. 

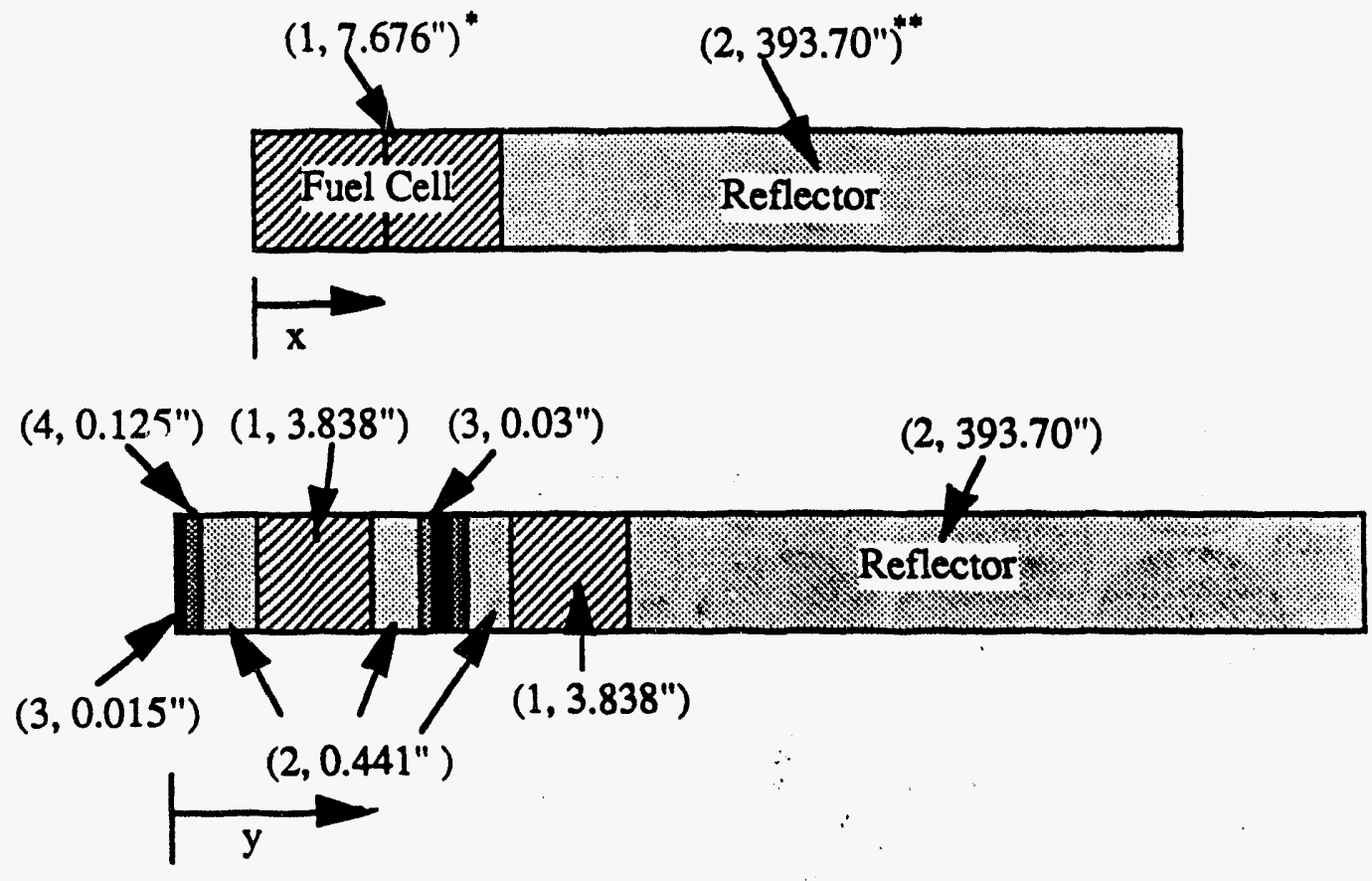

\begin{tabular}{|c|l|}
\hline Region Number & Materials \\
\hline 1 & Fuel Cell \\
2 & Water \\
3 & Cadmium \\
4 & Aluminium \\
\hline
\end{tabular}

- The first number in parenthesis indicates region number and the second thickness of each region in inch.

** 393.70 inch $(=1000 \mathrm{~cm})$ corresponds to large value of reflector thickness.

Figure 18. Slab model for equivalent lattice of $4 \times 4$ Mark 16 assemblies with Al clad Cd sheets (dotted rectangle in Figure 16) for transverse buckling search as modeled in INPUT. TGAL. BTCH . mk 16-c2.1 and INPUT. TGAL. BTCH . mk 16c2. 2 . 
Table 1. Material densities and Uranium isotope compositions of Mark 16 assembly

\begin{tabular}{|c|c|c|c|c|c|c|}
\hline \multicolumn{7}{|c|}{ Atom Ratio of $U^{236 / U^{235}}=0.19$} \\
\hline \multirow{2}{*}{ Materials } & \multirow{2}{*}{$\begin{array}{c}\text { Density * } \\
\text { in } \mathrm{gm} \mathrm{U}^{235 / \mathrm{ft}}\end{array}$} & \multicolumn{5}{|c|}{ Isotope Composition } \\
\hline & & U233 & $U^{234}$ & U235 & U236 & U238 \\
\hline Inner Fuel & InFo & 0.0 & 0.014 & 0.742 & 0.145 & 0.099 \\
\hline Middle Fuel & Deleted & 0.0 & 0.015 & 0.728 & 0.154 & 0.103 \\
\hline Outer Fuel & & 0.0 & 0.014 & 0.762 & 0.130 & 0.094 \\
\hline
\end{tabular}

\begin{tabular}{|c|c|c|c|c|c|c|}
\hline \multicolumn{7}{|c|}{ Atom Ratio of $U^{236} / \mathrm{U}^{235}=0.74$} \\
\hline \multirow{2}{*}{ Materials } & \multirow{2}{*}{$\begin{array}{l}\text { Density } \\
\text { in gm U235/ft }\end{array}$} & \multicolumn{5}{|c|}{ Isotope Composition } \\
\hline & & U233 & $\mathrm{U} 234$ & U235 & U236 & U238 \\
\hline Inner Fuel & \multirow{3}{*}{$\begin{array}{l}\text { InFo } \\
\text { Deleted }\end{array}$} & 0.0 & 0.016 & 0.480 & 0.357 & 0.147 \\
\hline Middle Fuel & & 0.0 & 0.016 & 0.480 & 0.357 & 0.147 \\
\hline Outer Fuel & & 0.0 & 0.016 & 0.480 & 0.357 & 0.147 \\
\hline \multicolumn{7}{|c|}{ Atom Ratio of $U^{236} / \mathrm{U}^{235}=0.0$ (Oralloy) } \\
\hline \multirow[t]{2}{*}{ Materials } & \multirow{2}{*}{$\begin{array}{c}\text { Density } \\
\text { in gm U235/ft }\end{array}$} & \multicolumn{5}{|c|}{ Isotope Composition } \\
\hline & & $U^{233}$ & $\mathrm{U}^{234}$ & $U^{235}$ & $U^{236}$ & $U^{238}$ \\
\hline Inner Fuel & IAPFO & 0.0 & 0.010 & 0.920 & 0.0 & 0.070 \\
\hline Middle Fuel & DeleTed & 0.0 & 0.010 & 0.920 & 0.0 & 0.070 \\
\hline Outer Fuel & & 0.0 & 0.010 & 0.920 & 0.0 & 0.070 \\
\hline
\end{tabular}

* Density of Aluminium cladding material is $2.7 \mathrm{gm} / \mathrm{cm}^{3}$.

- Note that aluminum component of $\mathrm{U}-\mathrm{Al}$ fuel region is calculated by KOKO using inputted geometry, standard formulas, and uranium and aluminum densities.

- Density of cadmium sheet was taken as $8.642 \mathrm{gm} / \mathrm{cm}^{3}$, the value specified in Reference 1 for the predefined TGAN macroscopic cross section set. 
Table 2. MGBS-TGAL results for various arrays and fuel compositions of Mark 16 assembly

\begin{tabular}{|c|c|c|c|c|}
\hline \multirow{2}{*}{$\begin{array}{l}\text { Atom Ratio } \\
\text { of } U^{236} / U^{235}\end{array}$} & \multirow{2}{*}{ Fuel Assembly Arrays a } & \multirow{2}{*}{$\mathrm{K}^{2}, \mathrm{~cm}^{2}$} & \multicolumn{2}{|c|}{$\mathrm{K}_{\text {eff }}$} \\
\hline & & & Original MGBSb & Alternate MGBS \\
\hline \multirow[t]{4}{*}{0.19} & $2 \times 3(3.700 " \times 3.700 ")$ & $5.350 \times 10^{-4}$ & $1.0637(1.0637)^{d}$ & $1.0464(1.0464)^{d}$ \\
\hline & $2 \times 3(3.838 "$ x $3.838 ")$ & $3.400 \times 10^{-4}$ & $1.0712(1.0712)$ & $1.0563(1.0563)$ \\
\hline & 2 × 3 (4.187" x 4.187") & $3.350 \times 10^{-4}$ & $1.0765(1.0765)$ & $1.0664(1.0664)$ \\
\hline & $2 \times 4\left(4.536^{\prime \prime} \times 4.536 "\right)$ & $-4.500 \times 10^{-4}$ & 595) & $1.0641(1.0641)$ \\
\hline 0.74 & $2 \times 3\left(4.187^{\prime \prime} \times 4.187 "\right)$ & $9.700 \times 10^{-4}$ & 5884) & 1.04 \\
\hline \multirow{4}{*}{$\begin{array}{l}0.0 \\
\text { (Oralloy) }\end{array}$} & $2 \times 2\left(3.700^{\prime \prime} \times 3.700^{\prime \prime}\right)$ & $1.520 \times 10^{-3}$ & $1.0766(1.0766)$ & $1.0512(1.0512)$ \\
\hline & $2 \times 2\left(3.838^{\prime \prime}\right.$ x 3.838") & $1.360 \times 10^{-3}$ & $1.0884(1.0883)$ & $1.0664(1.0664)$ \\
\hline & $2 \times 2\left(4.187^{\prime \prime} \times 4.187 "\right)$ & $8.900 \times 10^{-4}$ & 1.0897 (1.0897) & $1.0732(1.0732)$ \\
\hline & 36") & $1.250 \times 10^{-3}$ & 7798) & $1.0671(1.0671)$ \\
\hline \multirow[t]{3}{*}{0.19} & $2 \times 4\left(6.000^{\prime \prime} \times 3.700^{\prime \prime}\right)^{e}$ & $1.295 \times 10-3$ & 1.0789 (1.0789) & $1.0629(1.0629)$ \\
\hline & $3 \times 3\left(6.000^{\prime \prime} \times 3.700^{\prime \prime}\right)$ & $9.100 \times 10^{-4}$ & $1.0793(1.0793)$ & $1.0617(1.0618)$ \\
\hline & (0" x 3.838") & $1.010 \times 10^{-3}$ & $1.0968(1.0968)$ & $1.0842(1.0842)$ \\
\hline $\begin{array}{l}0.0 \\
\text { (Oralloy) } \\
\end{array}$ & $3 \times 3\left(7.500^{\prime \prime} \times 3.700^{\prime \prime}\right)$ & $1.950 \times 10^{-3}$ & $1.0947(1.0947)$ & $1.0758(1.0758)$ \\
\hline $\begin{array}{l}0.19 \\
\text { (with } \\
\text { Cd sheets }\end{array}$ & $\begin{array}{l}4 \times 4\left(5.000^{\prime \prime} \times 3.700^{\prime \prime}\right) \\
4 \times 4\left(5.000^{\prime \prime} \times 3.838^{\prime \prime}\right)\end{array}$ & $\begin{array}{l}8.000 \times 10^{-4} \\
9.500 \times 10^{-4}\end{array}$ & $\begin{array}{l}1.0806(1.0806) \\
1.0945(1.0946) \\
\end{array}$ & $\frac{1.0771}{1.0983}(1.0772)$ \\
\hline
\end{tabular}

a No. of rows $x$ No. of assemblies per row (Pitch of rows in inch $x$ Pitch in row in inch)

b MGBS-TGAL combination with original MGBS cross sections.

c MGBS-TGAL combination with alternate MGBS cross sections.

d The number in parentheses is H. K. Clark's result (DPST-83-1025)

(Underlined values ( 4 cases) indicate the cases with differences between $\mathrm{HKC}$ results and current calculations.)

e The example cases are indicated by boldfaced letter. 
SRT-CMA-930058

Page 27 of 29

October 25, 1993

Table 3. Job number list of microfiche output files

\begin{tabular}{|c|c|c|c|c|}
\hline \multirow{2}{*}{$\begin{array}{l}\text { Atom Ratio } \\
\text { of } U^{236} / U^{235}\end{array}$} & \multirow{2}{*}{ Fuel Assembly Arrays ${ }^{a}$} & \multirow{2}{*}{$\mathrm{k}^{2}, \mathrm{~cm}^{2}$} & \multicolumn{2}{|c|}{ Microfiche Job Number } \\
\hline & & & Original MGBS ${ }^{b}$ & Alternate MGBSc \\
\hline \multirow[t]{4}{*}{0.19} & $2 \times 3\left(3.700^{\prime \prime} \times 3.700^{\prime \prime}\right)$ & $5.350 \times 10^{-4}$ & 0054 & 5878 \\
\hline & 2 × $3(3.838 "$ x 3.838") & $3.400 \times 10^{-4}$ & 0078 & 5752 \\
\hline & $2 \times 3$ (4.187" x 4.187") & $3.350 \times 10^{-4}$ & 0083 & 6224 \\
\hline & $2 \times 4\left(4.536^{\prime \prime} \times 4.536^{\prime \prime}\right)$ & $-4.500 \times 10^{-4}$ & 0084 & 6384 \\
\hline 0.74 & $2 \times 3\left(4.187^{\prime \prime} \times 4.187^{\prime \prime}\right)$ & $9.700 \times 10^{-4}$ & 0094 & 9624 \\
\hline \multirow{4}{*}{$\begin{array}{l}0.0 \\
\text { (Oralloy) }\end{array}$} & $2 \times 2\left(3.700^{\prime \prime} \times 3.700^{\prime \prime}\right)$ & $1.520 \times 10^{-3}$ & 1600 & 9679 \\
\hline & $2 \times 2\left(3.838^{\prime \prime} \times 3.838^{\prime \prime}\right)$ & $1.360 \times 10^{-3}$ & 1622 & 9746 \\
\hline & $2 \times 2(4.187 " \times 4.187 ")$ & $8.900 \times 10^{-4}$ & 1642 & 9774 \\
\hline & $2 \times 2\left(4.536^{\prime \prime} \times 4.536^{\prime \prime}\right)$ & $1.250 \times 10^{-3}$ & 1653 & 9806 \\
\hline \multirow[t]{3}{*}{0.19} & $2 \times 4\left(6.000^{\prime \prime} \times 3.100 "\right)$ & $1.295 \times 10^{-3}$ & 5124 & 5111 \\
\hline & $3 \times 3\left(6.000^{\prime \prime} \times 3.700^{\prime \prime}\right)$ & $9.100 \times 10^{-4}$ & 5282 & 5281 \\
\hline & $3 \times 3\left(6.000^{\prime \prime} \times 3.838^{\prime \prime}\right)$ & $1.010 \times 10^{-3}$ & 5194 & 5189 \\
\hline $\begin{array}{l}0.0 \\
\text { (Oralloy) }\end{array}$ & $3 \times 3\left(7.500^{\prime \prime} \times 3.700^{\prime \prime}\right)$ & $1.950 \times 10^{-3}$ & 5223 & 5214 \\
\hline $\begin{array}{l}0.19 \\
\text { (with }\end{array}$ & {$\left[\begin{array}{l}4 \times 4\left(5.000^{\prime \prime} \times 3.700^{\prime \prime}\right) \\
4 \times 4\left(5.000^{\prime \prime} \times 3.838^{\prime \prime}\right)\end{array}\right.$} & $\begin{array}{l}8.000 \times 10^{-4} \\
0500 \times 10^{-4}\end{array}$ & 5258 & 5249 \\
\hline Cd Sheets) & $4 \times 4\left(5.000^{\prime \prime} \times 3.838^{\prime \prime}\right)$ & $9.500 \times 10^{-4}$ & 5266 & 5262 \\
\hline
\end{tabular}

a No. of rows $\mathrm{x}$ No. of assemblies per row (Pitch of rows in inch $\mathrm{x}$ Pitch in row in inch)

b MGBS-TGAL combination with original MGBS cross sections.

c MGBS-TGAL combination with alternate MGBS cross sections. 
SRT-CMA-930058

Page 28 of 29

October 25, 1993

\section{APPENDIX}

- Relationship of Measured Parameter $K^{2}$ to Axial Buckling $B_{2}^{2}$ of an Array

The thermal neutron flux distribution in an exponential pile $e^{4.5}$ is determined by the steady-state diffusion equation.

$\nabla^{2} \Phi(x, y, z)+B_{m}^{2} \Phi(x, y, z)=0$

where $B_{m}{ }^{2}<B_{g}{ }^{2}$ for a subcritical system and $B_{m}{ }^{2}=B_{g}{ }^{2}$ for a critical system.

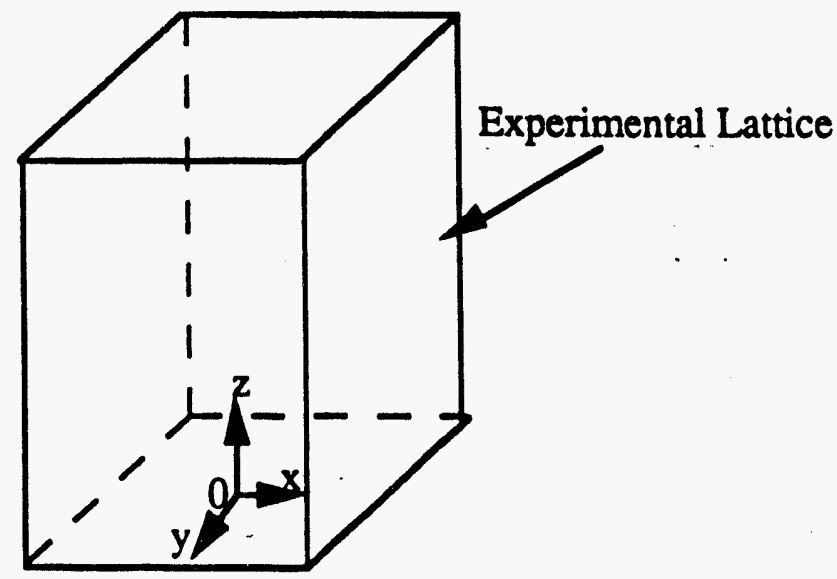

Figure A.1. Rectangular parallelepiped block in the Cartesian coordinate system.

Assuming that the function $\Phi$ is separable under the Cartesian coordinate system in Figure A.1,

$\Phi(\mathrm{x}, \mathrm{y}, \mathrm{z})=\phi_{1}(\mathrm{x}) \phi_{2}(\mathrm{y}) \phi_{3}(\mathrm{z})$

After substituting equation A.2 into equation $A .1$ and dividing the resulting equation by $\phi_{1} \phi_{2} \phi_{3}$, the terms in $\phi_{1}, \phi_{2}$, and $\phi_{3}$ may then be set equal to the constants, $-B_{x}{ }^{2},-B_{y}{ }^{2}$, and $\kappa^{2}$, respectively.

$\frac{1}{\phi_{1}} \frac{\mathrm{d}^{2}}{\mathrm{dx}^{2}} \phi_{1}=-\mathrm{B}_{\mathrm{x}}{ }^{2}$

$\frac{1}{\phi_{2}} \frac{\mathrm{d}^{2}}{\mathrm{dy}^{2}} \phi_{2}=-\mathrm{B}_{\mathrm{y}}^{2}$

$\frac{1}{\phi_{3}} \frac{d^{2}}{d z^{2}} \phi_{3}=\kappa^{2}$

Substituting equation A.3 into equation A.1, $B_{m}{ }^{2}$ becomes

$B_{m}^{2}=B_{x}^{2}+B_{y}{ }^{2}-\kappa^{2}$ 
Boundary conditions for the rectangular block in Figure A.1 are given as

$\phi_{1}(x= \pm a / 2)=0$

$\phi_{2}(y= \pm b / 2)=0$

$\phi_{3}(z=0)=\phi_{30}$ and $\phi_{3}(z=c)=0$

where $a, b$, and $c$ in equations A.5, A.6, and A.7 are the physical dimensions including the extrapolated distances along the $x-, y-$, and $z$-directions.

Applying the boundary conditions (equations A.5 to A.7) to the separated equation A.3, the fundamental functional form for the neutron flux in the exponential experiment becomes

$$
\begin{aligned}
\Phi(x, y, z) & =\phi_{1}(x) \phi_{2}(y) \phi_{3}(z) \\
& =A \cos \left(B_{x} x\right) \cos \left(B_{y} y\right) \sinh \kappa(c-z)
\end{aligned}
$$

where

$$
B_{x}=\frac{\pi}{a} \text { and } B_{y}=\frac{\pi}{b}
$$

At distances not too near the top of the rectangular block in Figure A.1 $(z<c)$, the $z$ direction function is approximated as

$$
\phi_{3}(z) \approx \mathrm{Ce}^{-\mathrm{kz}}
$$

where $\mathrm{C}$ is a constant and $\mathrm{K}$ is the determinable parameter from the exponential experiment.

The inverse value of $K$ in equation $A .10$ corresponds to the relaxation length of the neutrons, that is, the distance within which the neutron flux falls off by a factor of $e$ in the z-direction.

Substituting equation $\mathrm{A} .9$ into equation $\mathrm{A} .4$, the material buckling $\mathrm{Bm}^{2}$ becomes

$$
B_{m}^{2}=\left(\frac{\pi}{a}\right)^{2}+\left(\frac{\pi}{b}\right)^{2}-k^{2}
$$

For the rectangular block shown in Figure A.1, the geometrical buckling $\mathrm{B}_{\mathrm{g}}{ }^{2}$ is given as

$$
\mathrm{B}_{\mathrm{g}}^{2}=\mathrm{B}_{\mathrm{x}}^{2}+\mathrm{B}_{\mathrm{y}}^{2}+\mathrm{B}_{\mathrm{z}}^{2}
$$

For a critical system $\left(B_{m}{ }^{2}=B_{g}{ }^{2}\right)$, comparison of equations $A .11$ and $A .12$ shows that

$$
B_{z}^{2}=-k^{2}
$$




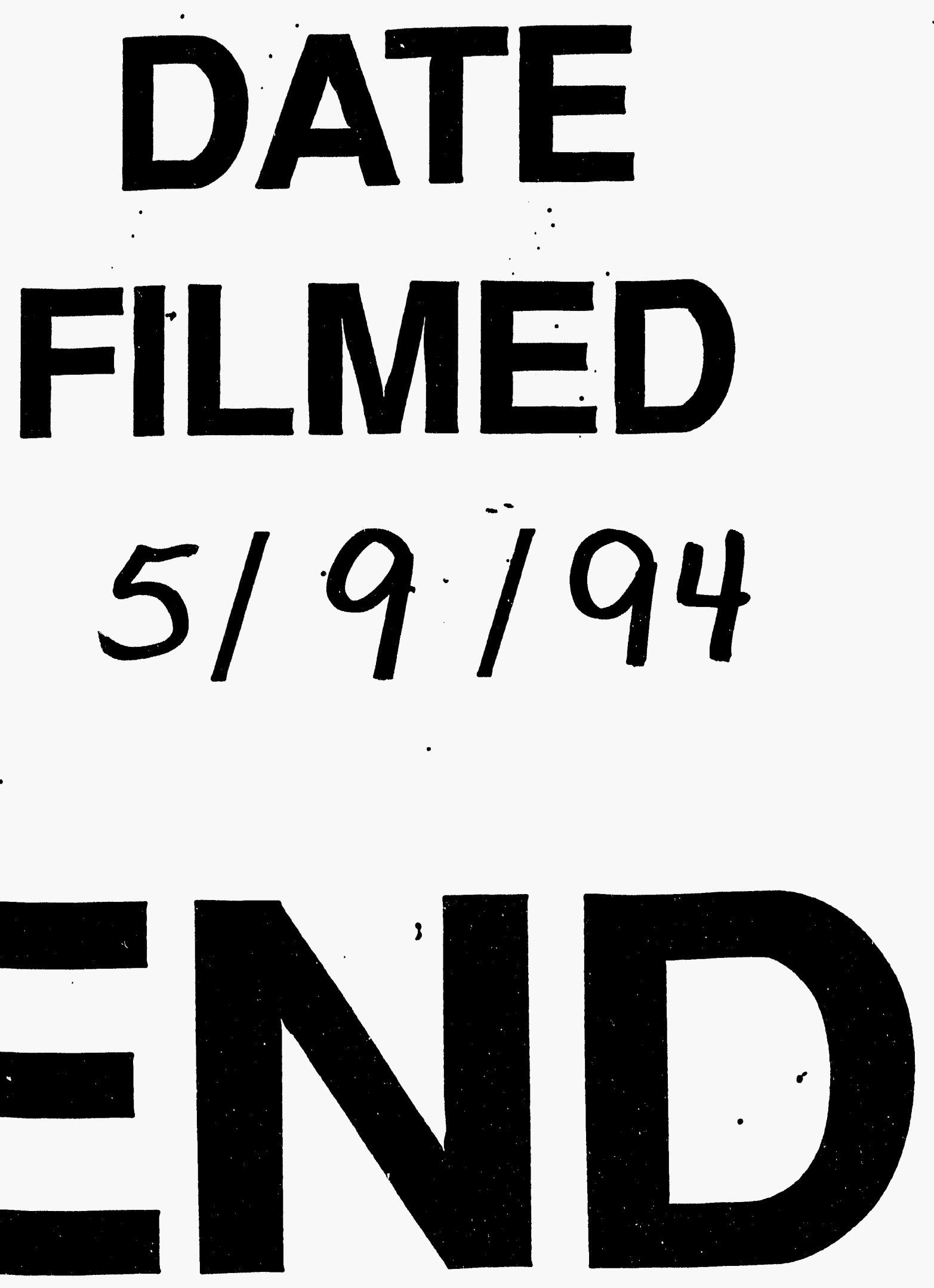




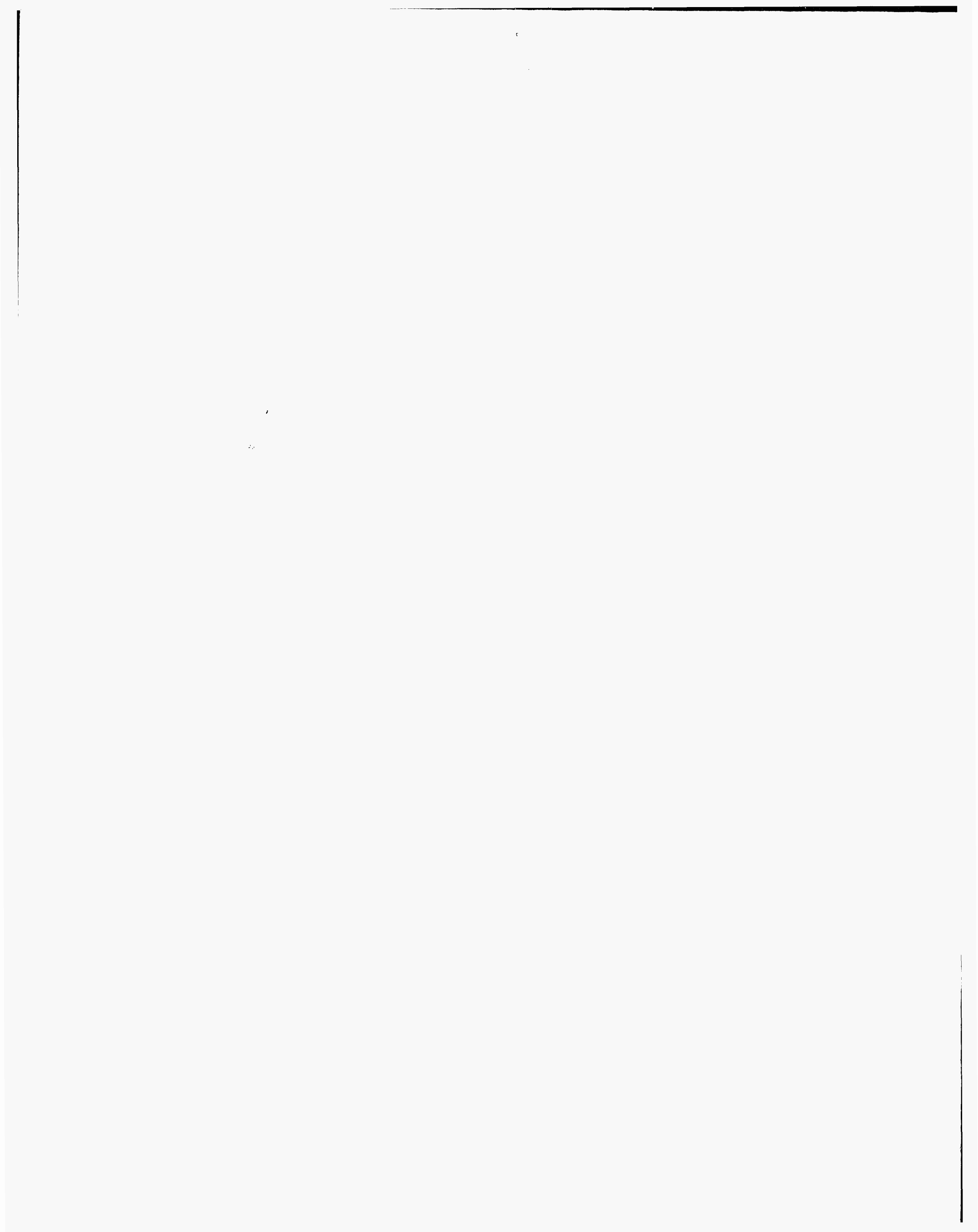

